\title{
A review of studies of the proteomes of circulating microparticles: key roles for galectin-3-binding protein-expressing microparticles in vascular diseases and systemic lupus erythematosus
}

\author{
Christoffer T. Nielsen ${ }^{1 *}$, Ole Østergaard ${ }^{2}$, Niclas S. Rasmussen ${ }^{1}$, Søren Jacobsen ${ }^{1}$ and Niels H. H. Heegaard ${ }^{2,3}$
}

\begin{abstract}
Subcellular microvesicles (MVs) have attracted increasing interest during the past decades. While initially considered as inert cellular debris, several important roles for MVs in physiological homeostasis, cancer, cardiovascular, and autoimmune diseases have been uncovered. Although still poorly understood, MVs are involved in trafficking of information from cell-to-cell, and are implicated in the regulation of immunity, thrombosis, and coagulation. Different subtypes of extracellular MVs exist. This review focuses on the cell membrane-derived shedded MVs (ranging in size from 200 to $1000 \mathrm{~nm}$ ) typically termed microparticles (MPs). The numbers and particularly the composition of MPs appear to reflect the state of their parental cells and MPs may therefore carry great potential as clinical biomarkers which can be elucidated and developed by proteomics in particular. Determination of the identity of the specific proteins and their quantities, i.e. the proteome, in complex samples such as MPs enables an in-depth characterization of the phenotypical changes of the MPs during disease states. At present, only a limited number of proteomic studies of circulating MPs have been carried out in healthy individuals and disease populations. Interestingly, these studies indicate that a small set of MP-proteins, in particular, overexpression of galectin-3-binding protein (G3BP) distinguish MPs in patients with venous thromboembolism and the systemic autoimmune disease, systemic lupus erythematosus (SLE). G3BP is important in cell-cell adhesion, clearance, and intercellular signaling. MPs overexpressing G3BP may thus be involved in thrombosis and hemostasis, vascular inflammation, and autoimmunity, further favoring G3BP as a marker of "pathogenic" MPs. MPs expressing G3BP may also hold a potential as biomarkers in other conditions such as cancer and chronic viral infections. This review highlights the methodology and results of the proteome studies behind these discoveries and places them in a pathophysiological and biomarker perspective.
\end{abstract}

Keywords: Proteomics, Mass spectrometry, Microparticles, Systemic lupus erythematosus, Lupus nephritis, Venous thrombosis, Atherosclerosis, Galectin-3-binding protein, Mac-2 binding protein, Alpha-2-macroglobulin, CD5 antigenlike protein

\section{Introduction: microvesicles-microparticles}

Microvesicles (MVs) are a heterogenous population of submicron membranous vesicles released from all types

\footnotetext{
*Correspondence: christoffertandrupnielsen@gmail.com

${ }^{1}$ Copenhagen Lupus and Vasculitis Clinic, Centre for Rheumatology and Spine Diseases, Rigshospitalet, Copenhagen University Hospital, Blegdamsvej 9, 2100 Copenhagen $\varnothing$, Denmark

Full list of author information is available at the end of the article
}

of cells both constitutively and during activation and apoptosis [1]. MVs are released from cytosolic organelles, such as granules, from the endoplasmic reticulum, and from multivesicular bodies and are also shed directly from the cell surface membrane [1]. Even though the field is rapidly growing, the limited knowledge about the different types of MVs, their formation, composition, fate, and function still hampers the definitions, terminology, 
and studies. The MVs that derive from the multivesicular bodies are termed exosomes and range in size from 40 to $100 \mathrm{~nm}$, while the larger MVs $(200-1000 \mathrm{~nm})$ shed from the cell surface are typically termed microparticles (MPs) [1]. In this review, we focus on human MP studies based on this definition.

MPs are composed of a complex mixture of proteins, glycoproteins, lipids, and RNA/DNA [2]. They carry many bioactive molecules, and their structure which is reminiscent of liposomes enhances their co-stimulatory properties similar to adjuvants in vaccines [3]. MPs interact with other cells, platelets, other MPs, and the extracellular matrix and facilitate intercellular communication. As examples, MPs can shuttle mRNA and miRNA to acceptor cells and regulate their protein translation, MPs serve as a major mobilizable reservoir of tissue factor (TF) and can initiate coagulation, and MPs can alter immune responses in autoimmune diseases, e.g. by triggering dendritic cells to release interferon- $\alpha$ (IFN- $\alpha$ ), a major effector cytokine in systemic lupus erythematosus (SLE) $[1,4,5]$. Most functional studies have been conducted in vitro by investigating subsets of MPs or specific surface molecules from MPs induced in cultured cells [6]. Functional MP studies ex vivo have been few [5]. Instead, investigations in patients have focused on quantitating cellular subsets of circulating MPs and correlating them to a specific disease or disease manifestation and thereby explore their pathogenic roles and/or biomarker potential [7]. Generally, MPs increase in numbers during cellular activation or apoptosis, but determining their numbers and origin have not proved specific or sensitive enough for biomarker use. More extensive and detailed characterization of the specific MP subpopulations is highly needed. Until now most studies have characterized MP subpopulations using cell-specific surface markers due to the paucity of other identified markers specific for subsets of MPs involved e.g. in pathological processes [8-10].

Unbiased in-depth characterization of DNA/RNA content, lipids, metabolites, and proteins may help unravel the MP-composition and the discovery of new markers of MPs that are involved in disease pathogenesis. Here, we review the methodology and results of proteomic discovery studies of human plasma MPs. We argue that a restricted set of candidate MP proteins, galectin-3-binding protein (G3BP) in particular, could prove highly useful as biomarkers and tools to understanding the role of MPs in the systemic autoimmune disease, systemic lupus erythematosus (SLE), and venous thromboembolism (VTE), and potentially also in cancer and chronic viral infections $[8,11-15]$. G3BP is a cysteine-rich scavenger receptor $[16,17]$. G3BP exerts its regulatory roles by binding to lectins, extracellular matrix proteins, and integrins [18-20]. G3BP is upregulated during cell activation, viral infections, cell death, and in cancer cells, and G3BP-expression could reflect an aberrant state of the parental cells, e.g. apoptosis [21-24]. In HIV and hepatitis $\mathrm{C}$, serum G3BP has been associated with a poorer outcome [22, 25-28]. G3BP plays important roles in cell-cell adhesion and intercellular signaling in the immune system and in cancer and metastasis [29-32]. Breast cancer cells in vitro release G3BP which promotes tumor cell aggregation and inhibition of peri-tumor fibrosis ultimately favoring metastasis [31, 33, 34]. In line with these observations, serum G3BP is associated with a poorer prognosis in non-Hodgkin lymphoma, lung and breast cancer $[33,35,36]$. In this review we focus on G3BPexpressing MPs in SLE and VTE. However, G3BP may hold far greater potential as a novel MP-biomarker in other conditions.

\section{Microparticle proteomics}

\section{Proteome strategies and methods}

The design, pre-analytical and analytical methodology, and the results of the circulating human MP proteome studies to date are presented in detail in Table 1. In all cases the MPs were isolated by centrifugation from plasma, in some cases combined with prior size exclusion chromatography. It must be noted, however, that the exact conditions (to the extent they are specified) differ, i.e. different anticoagulants and-in particulardifferent centrifugation conditions (time, temperature, volumes, and g-forces) were used. This makes it difficult to compare studies, even those that aim to characterize and establish MP proteomes of healthy individuals [3740]. So far, only one study has attempted a systematic optimization of MP isolation steps monitored by objective parameters such as number and reproducibility of protein identifications [40]. The incomparability of data between studies of circulating MPs in normal controls is compounded by the vastly different analytical conditions and data extraction methods (Table 1). Many studies rely on liquid chromatography-tandem mass spectrometry (LC-MS/MS) with no labeling and other studies use isobaric tags for relative and absolute quantitation (iTRAQ) or isotope-coded affinity tags (ICAT). Further, some studies use 1-D or 2-D gel electrophoresis as primary separation and then MALDI-qTOF MS or other MALDI-TOF configurations. The resulting number of identified proteins in normal circulating MPs consequently varies considerably from 151 [12] to more than 530 [11] and contrasts to the more than 1100 common proteins identified in studies on platelet MPs [41]. Also, only rudimentary information on reproducibility within and between runs is available. Further, no reference ranges of MP numbers, types and protein abundance 


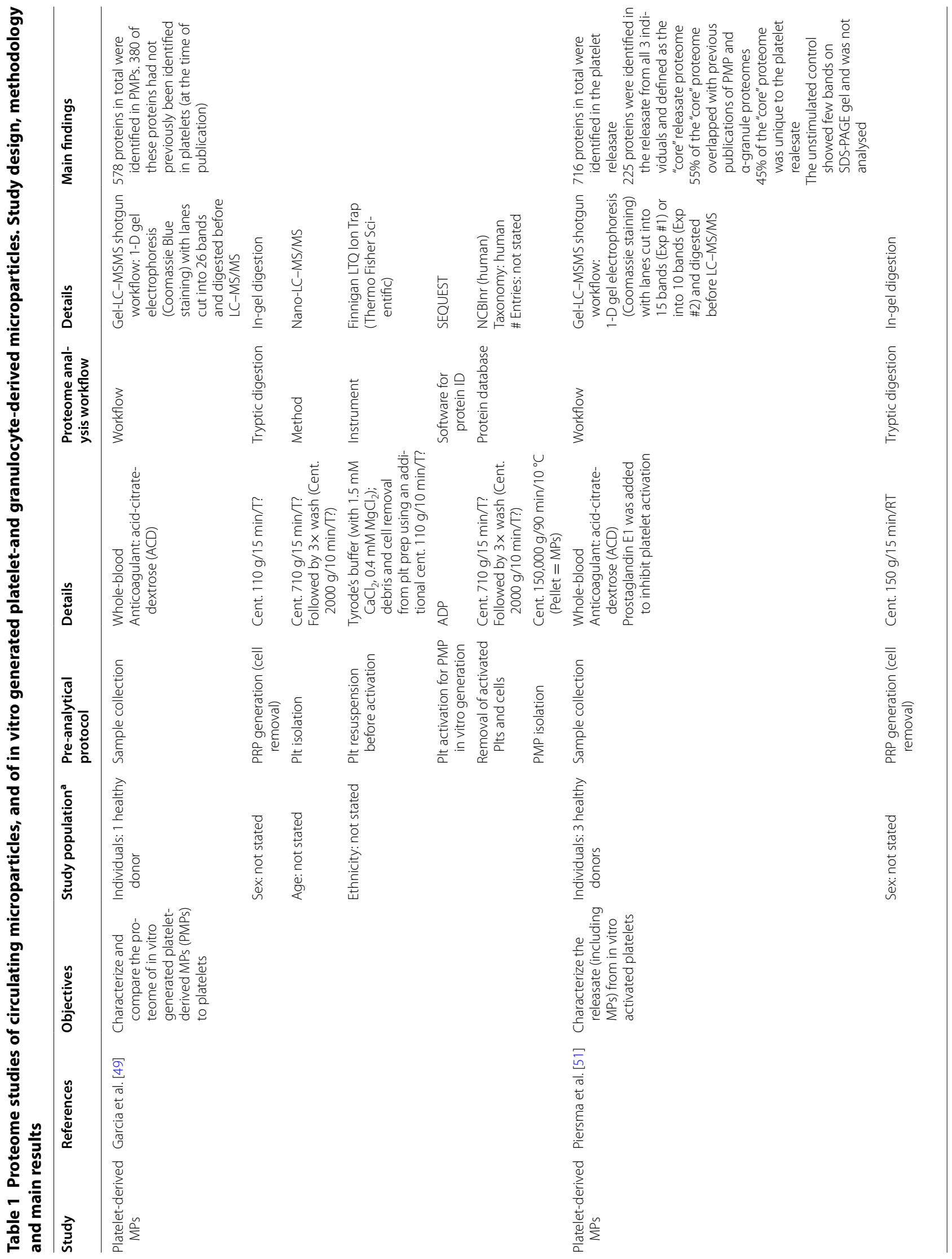




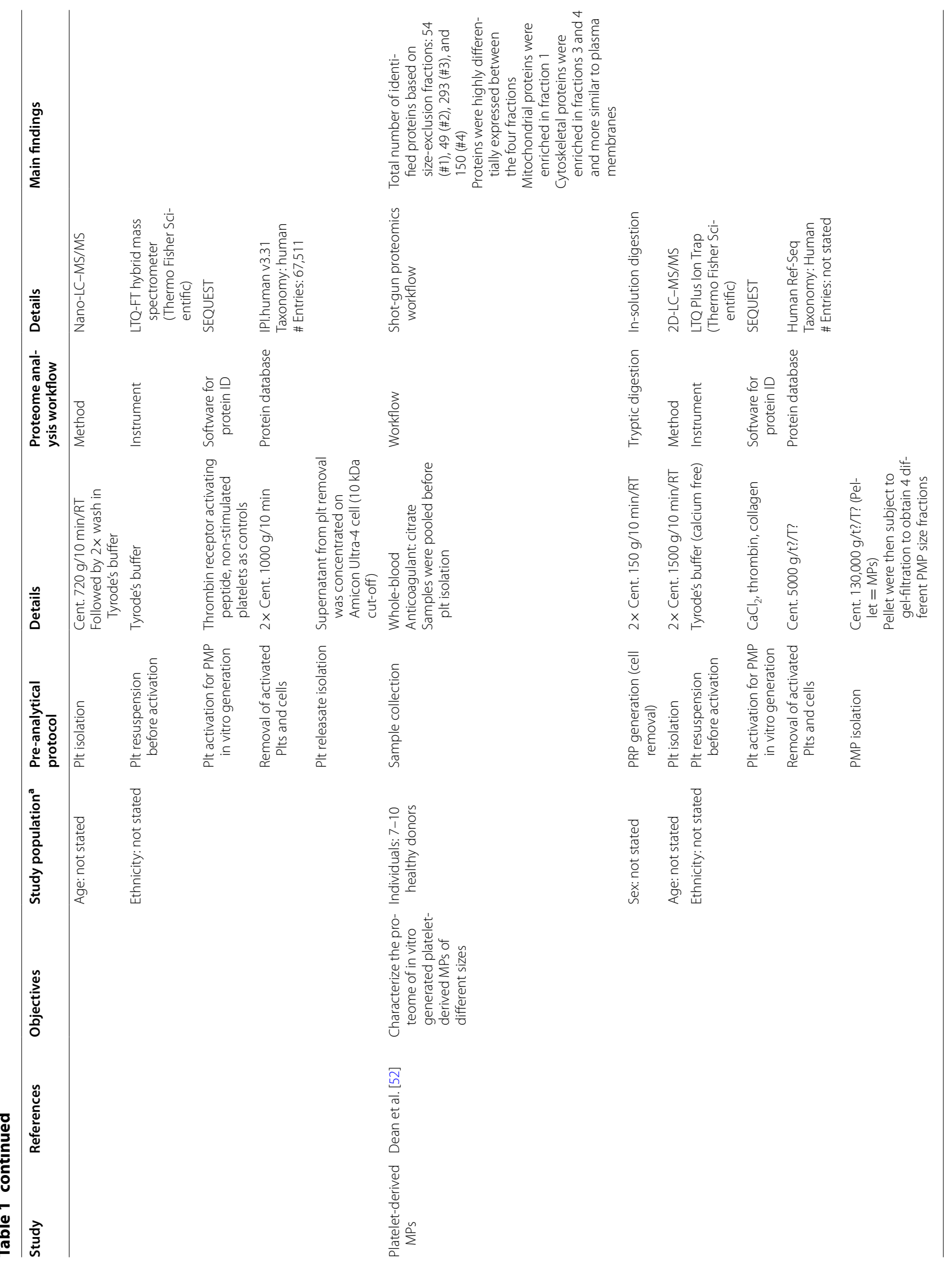




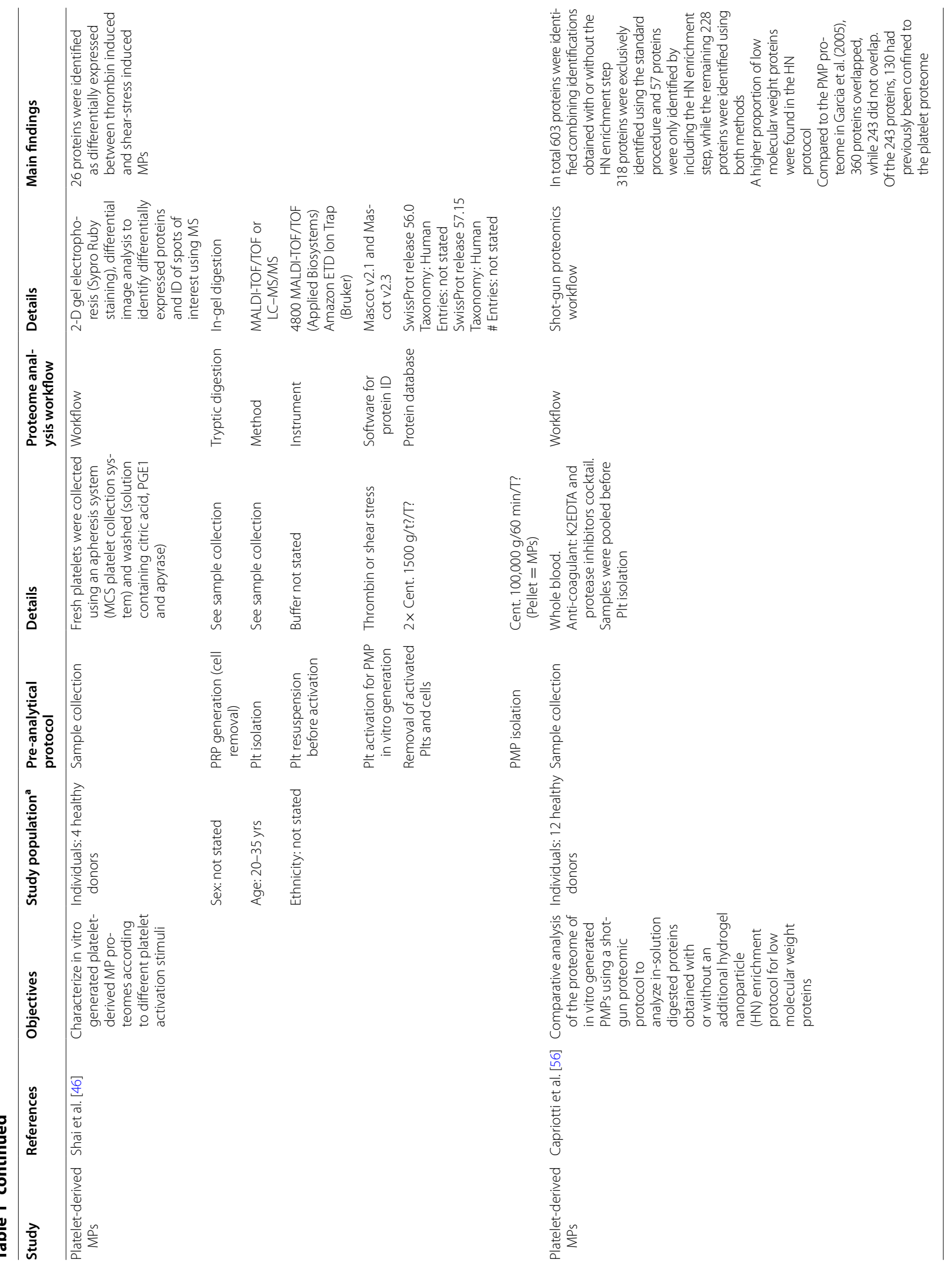




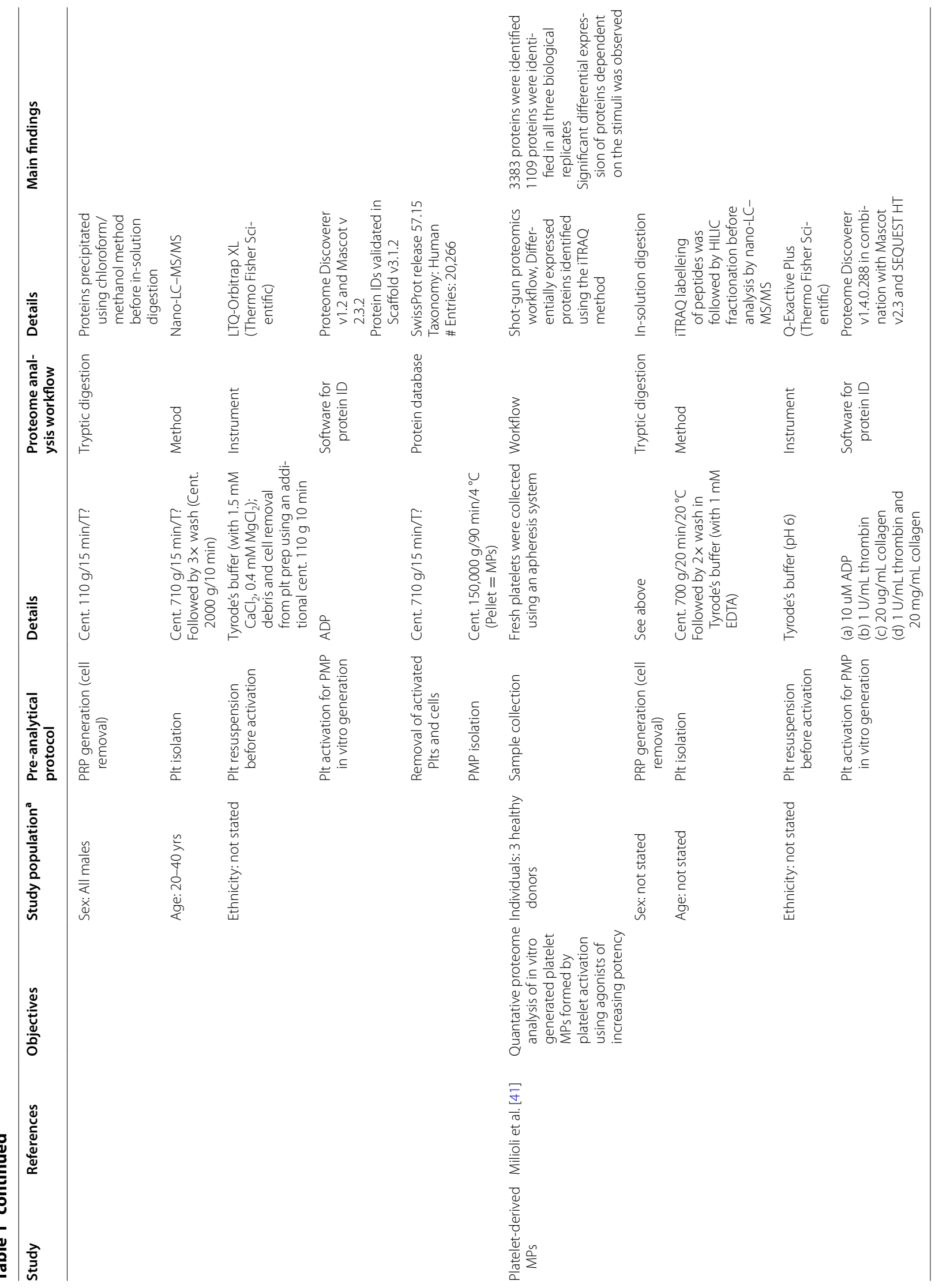




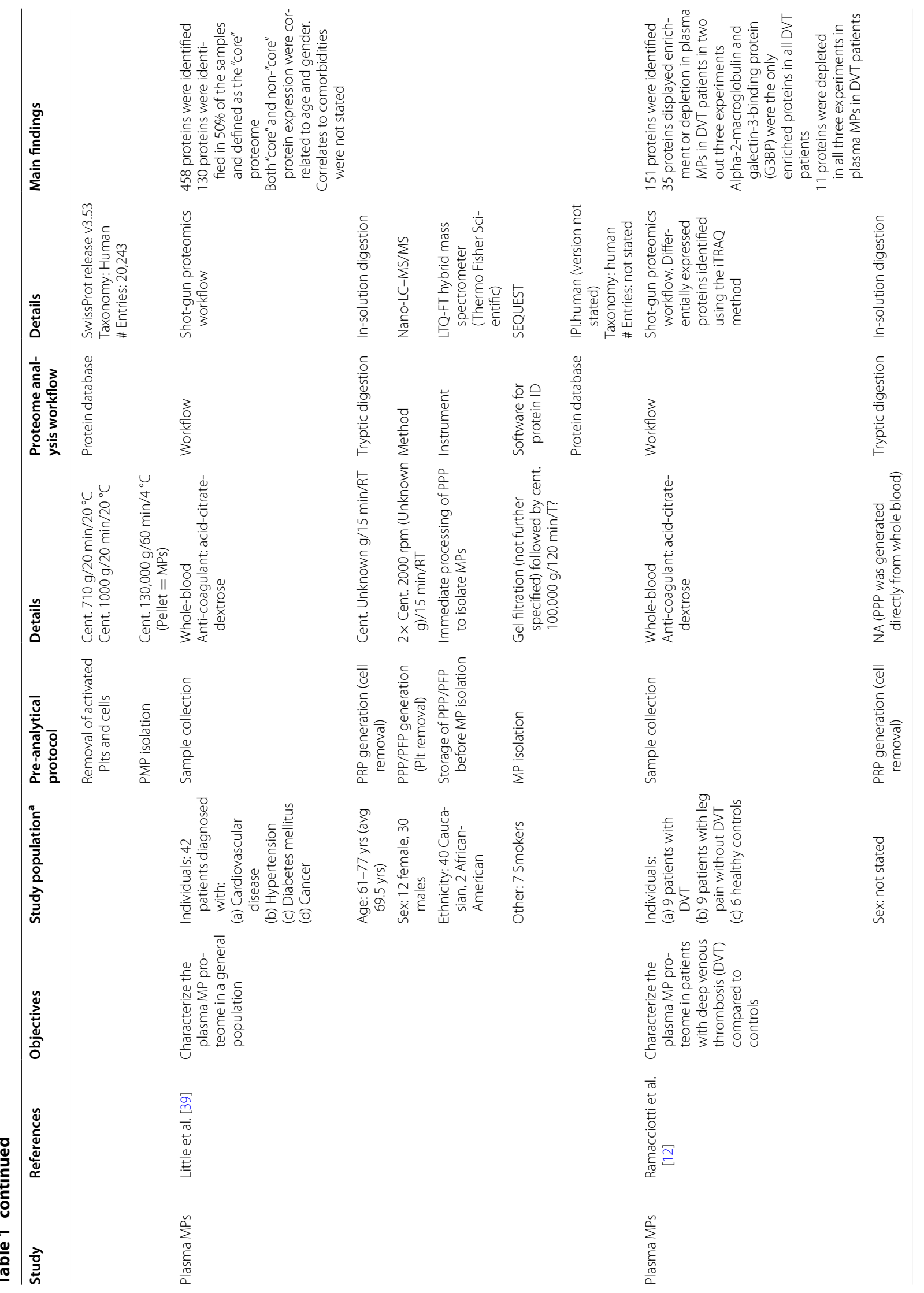




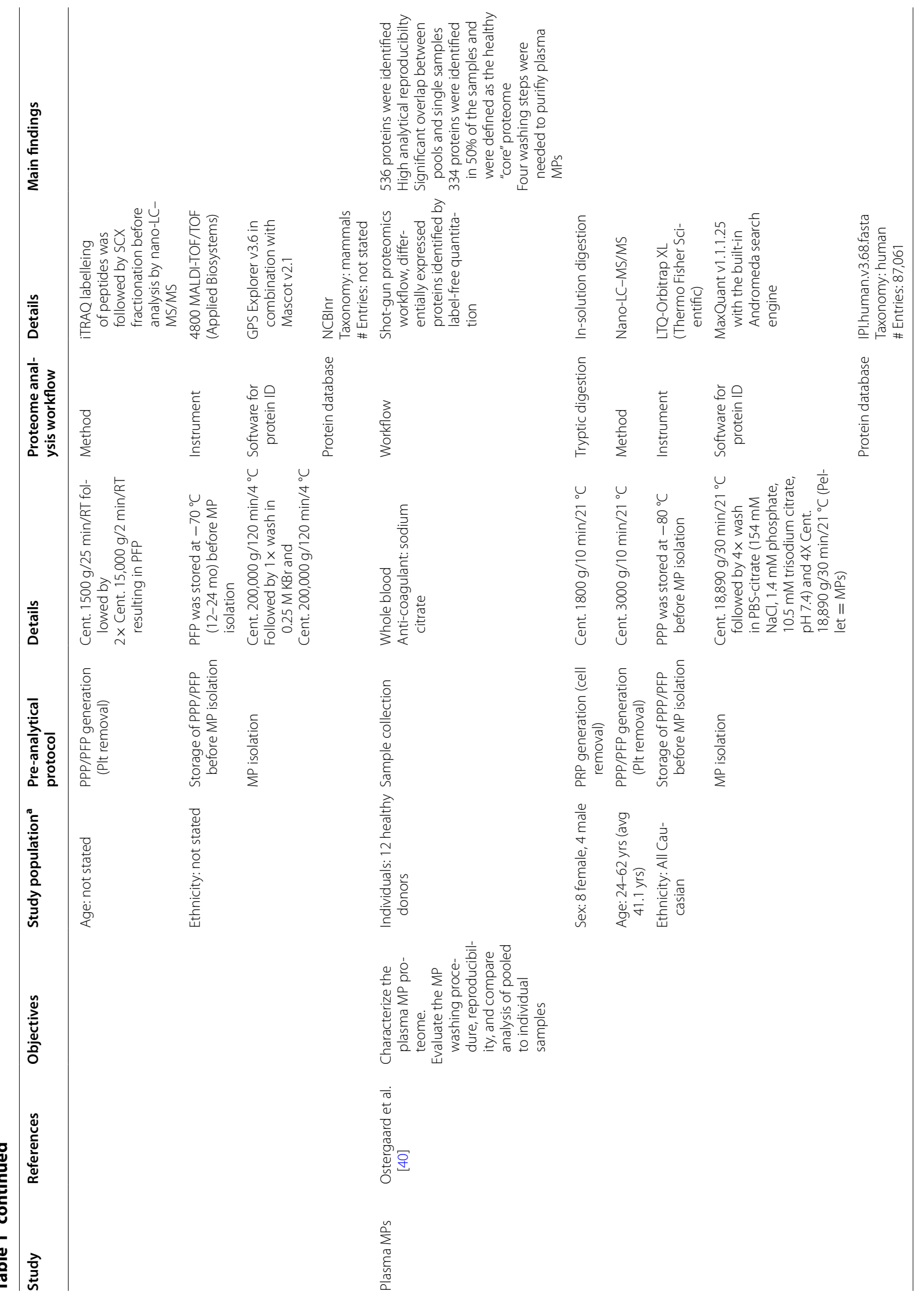




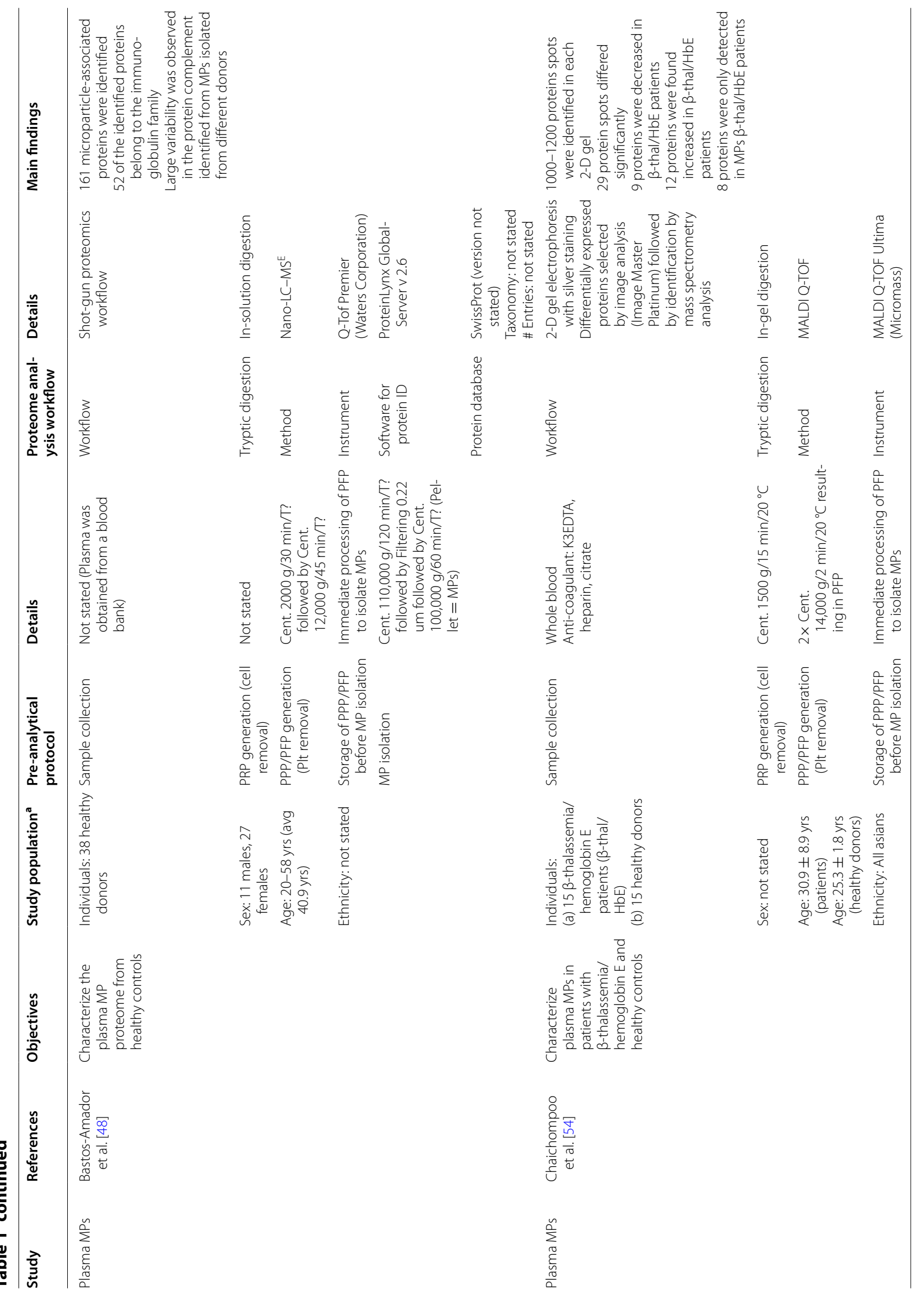




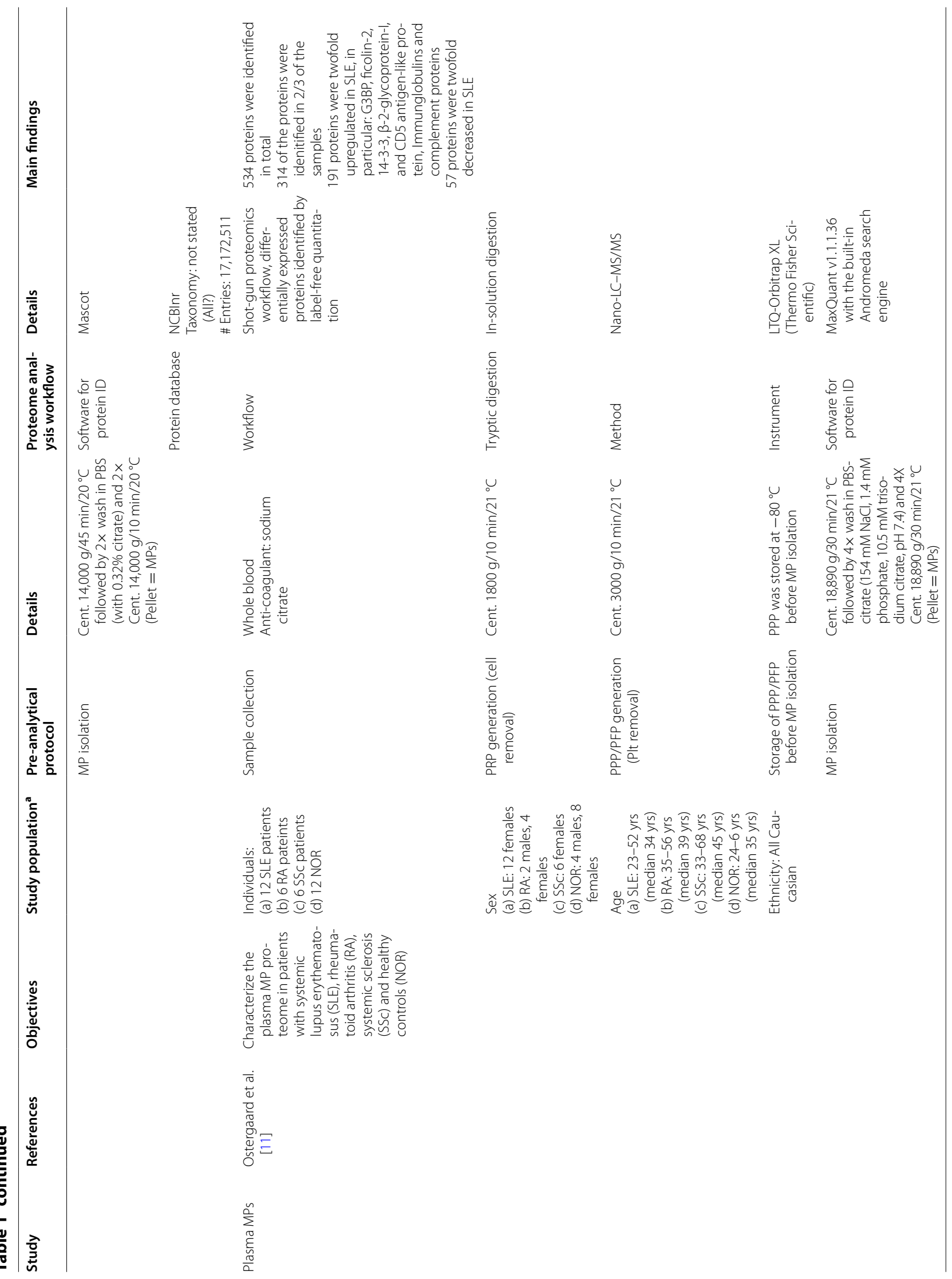




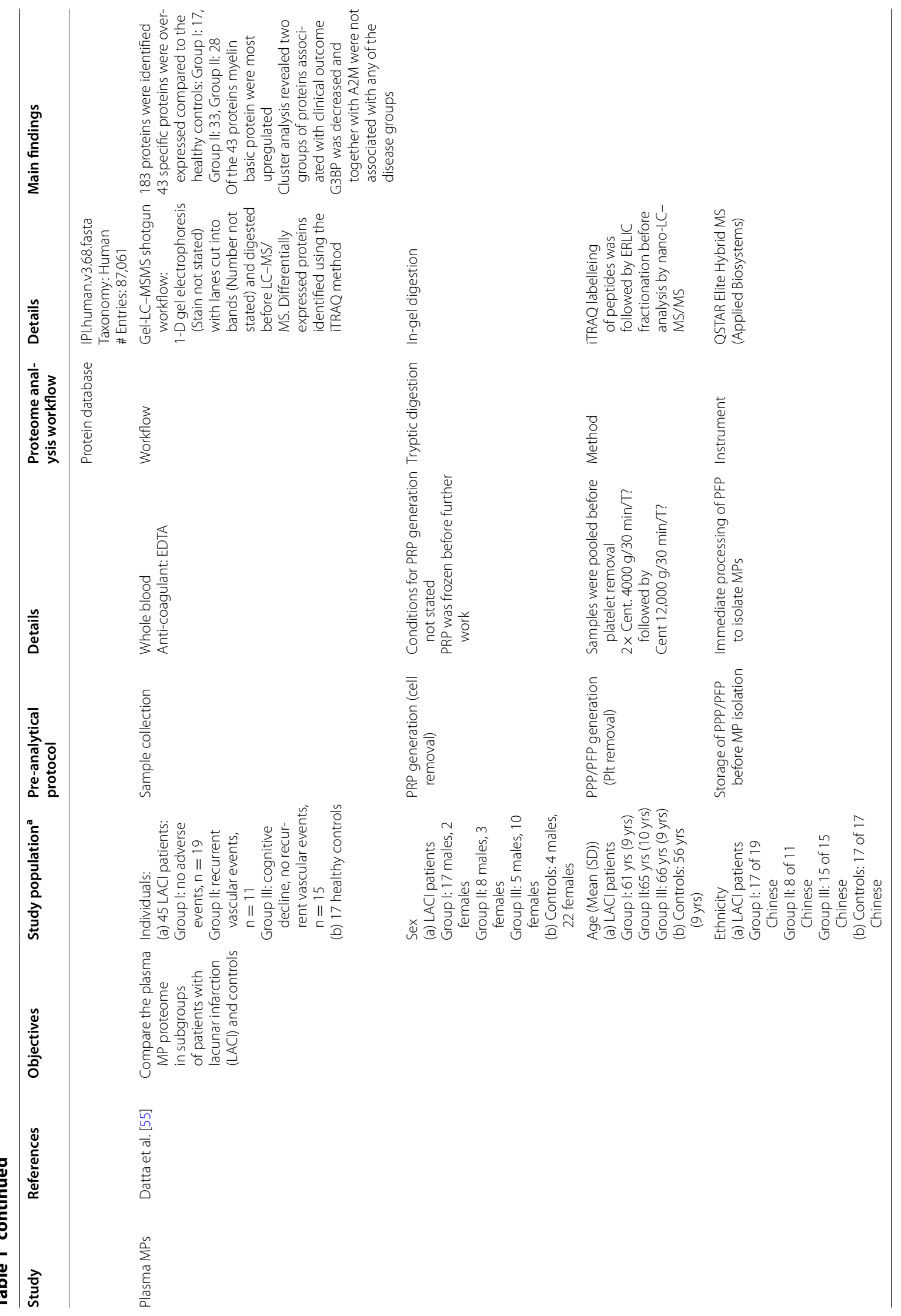




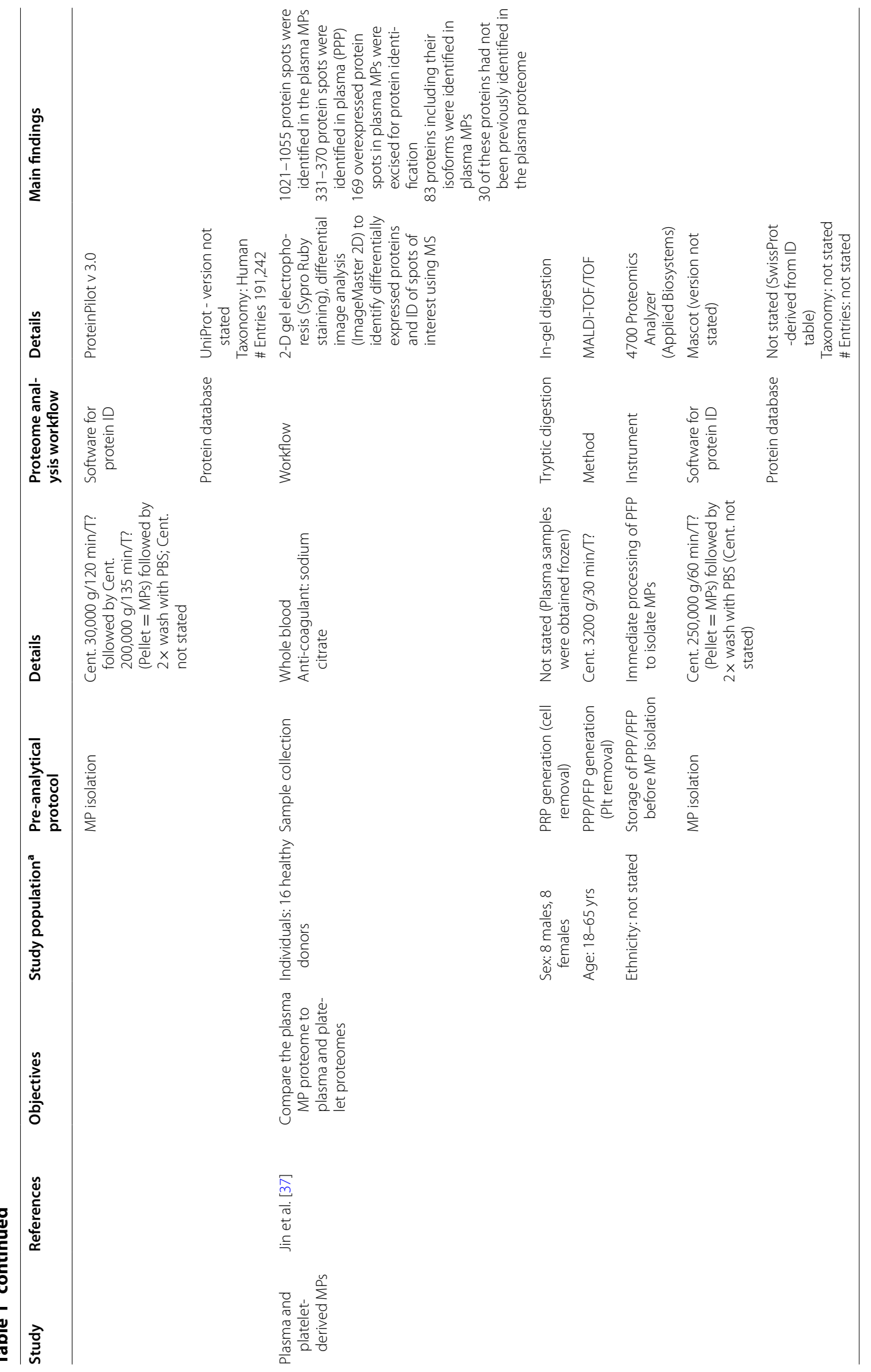




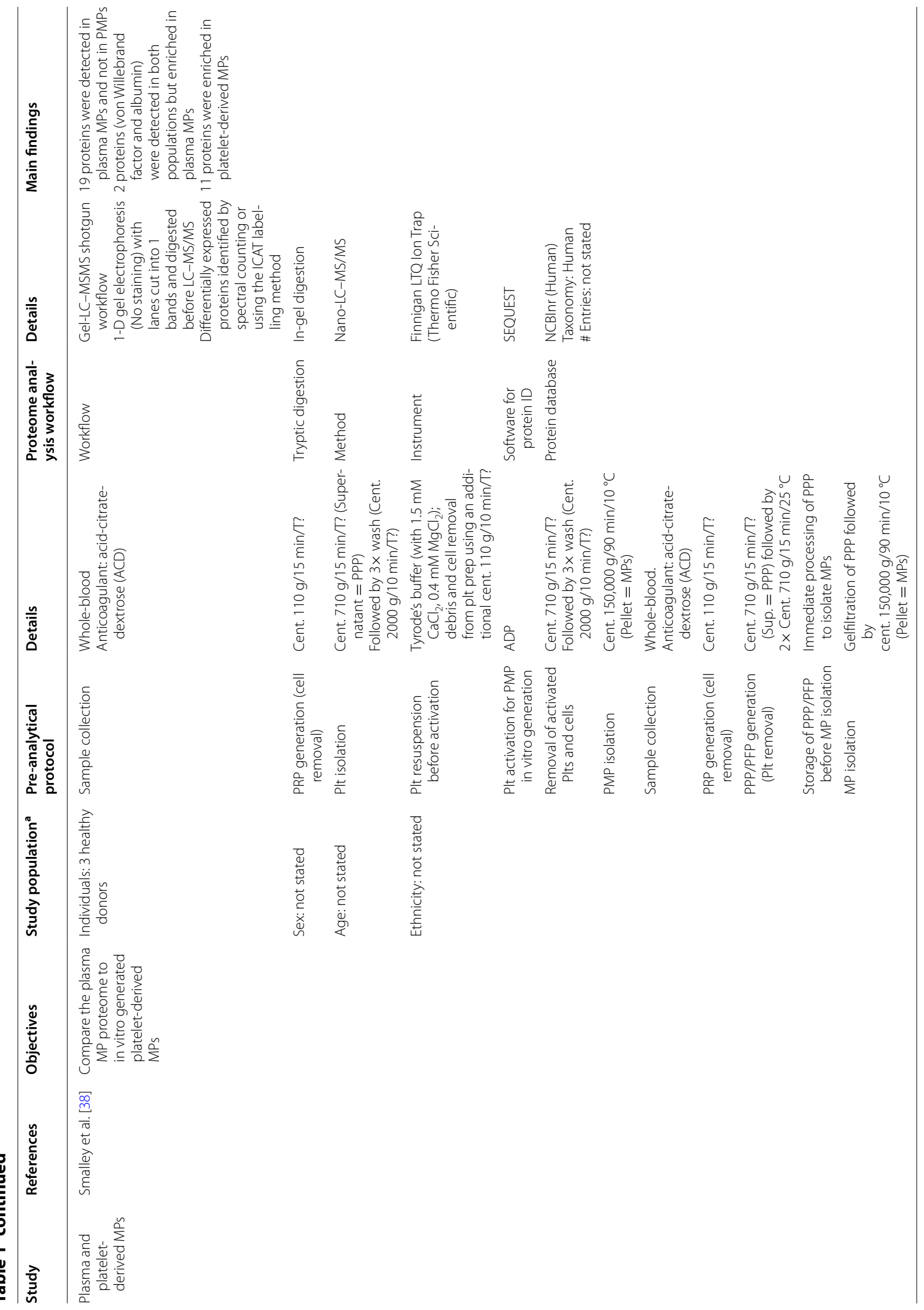




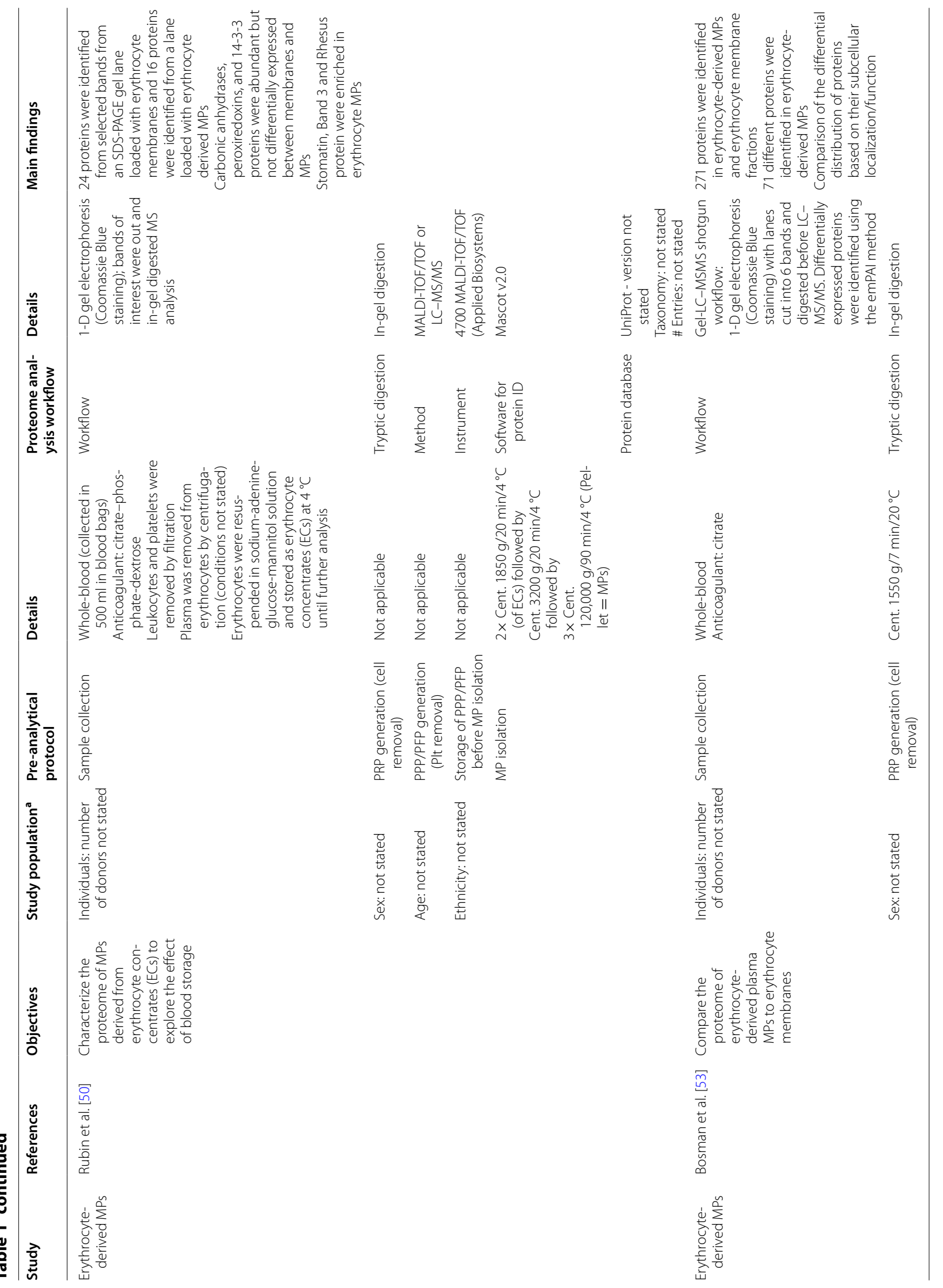




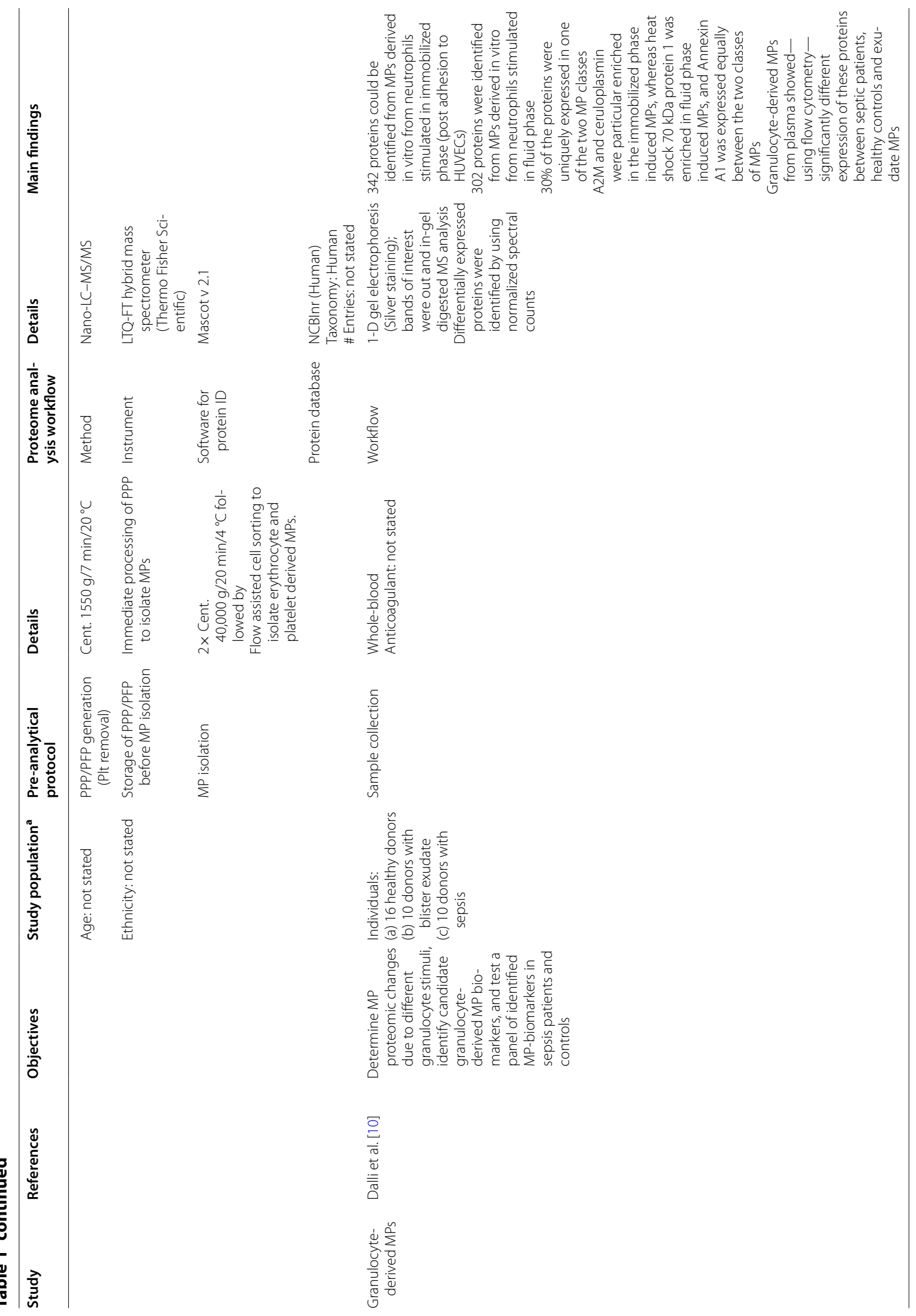




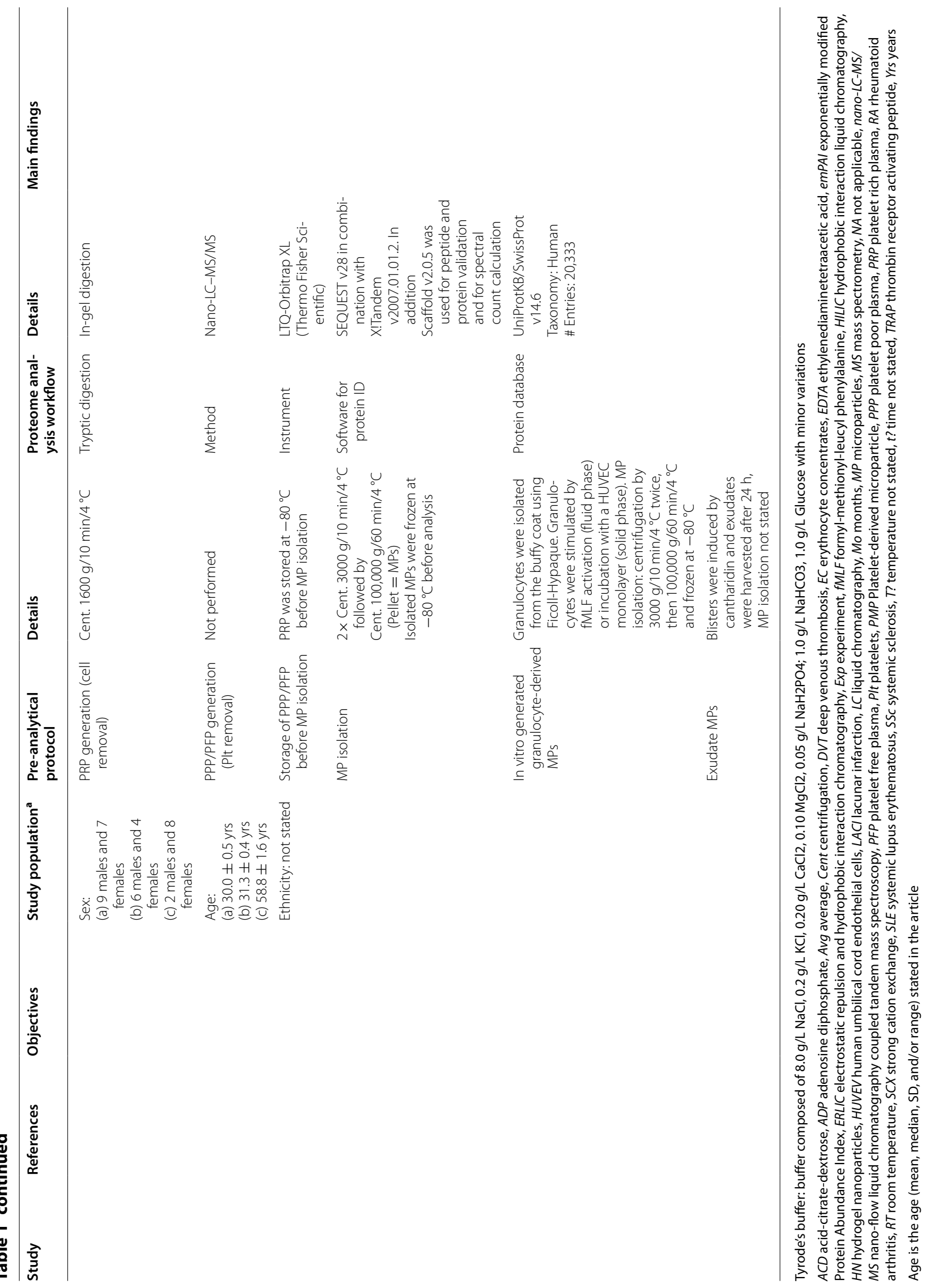


have been established in any population or patient group so far. Every study is a compromise between how extensively (how deeply) MP proteomes are characterized and the analysis time required for this weighed against the number of samples. This may favor pooling of samples in some cases but this should only be done after careful consideration of pros and cons [42]. Due to the complexity and heterogeneity of the MP compartment in blood samples some studies concentrate on the MPs produced by platelets, erythrocytes, or granulocytes. This is accomplished either by culturing the cells and studying the MPs they release after various stimuli or by isolating (e.g. by immunoaffinity methods) the specific MPs from plasma by virtue of their surface markers. By far the largest group of this type of studies deal with platelet-MPs derived from platelets isolated by centrifugation and then subjected to stimuli such as ADP, thrombin, and/or collagen [11-16]. Platelet MPs are normally among the most numerous in the circulation and are important in cardiovascular events both in venous and arterial thrombosis. Characterization of the ensemble of circulating MPs in plasma is addressed wholly or partly in eight of the studies included in Table 1 [17-24].

\section{The microparticle protein composition reflects the state of the parental cell}

Since the composition of MPs appears to reflect the state of the parental cell, the actual biomarker potential lies within unravelling compositional changes of MPs during disease states [43]. Mass spectrometry-based analysis has a great potential to decipher the dynamic components of MP proteomes. Thus, Peterson et al. [44] showed that approximately $10 \%$ of the proteins are differentially expressed in endothelial cell-derived MPs from human umbilical vascular endothelial cells (HUVECs) depending on the activation stimuli [tumor necrosis factor (TNF) or plasminogen activator inhibitor (PAI)]. Similar observations have been made in cultured non-malignant and malignant cell-lines, monocytes, erythrocytes, and platelets. Bernimoulin et al. stimulated monocytic THP-1 cells with lipopolysaccharide (LPS) or a soluble P-selectin chimera [45]. Fifty-two and 408 proteins were uniquely expressed in the corresponding MP fractions. In particular, differential expression of proteins from subcellular Iocations such as mitochondria and adhesion molecules were enriched in MP-fractions from the soluble P-selectin chimera stimulated cells. Another study, comparing the proteome of MPs from platelets stimulated by either shear-stress or by thrombin, revealed that 26 proteins were differentially expressed [46]. These proteins were particularly related to cell assembly and organization and to cell morphology. In line with this, Milioli et al.
[41] found that the platelet-derived MP protein content was highly dependent on the type of physiological agonist involved in platelet stimulation [thrombin, adenosine diphosphate (ADP), or collagen]. Interestingly, activation with stronger agonists resulted in platelet MP (PMP) overexpression of proteins related to platelet activation, while proteins involved in platelet degranulation and proteins from the electron transport chain were less abundant. In red blood cells, Prudent et al. [47] observed that calcium dependent proteins and annexins 4 and 5 were recruited in MPs generated by calcium stimulation compared to stored red blood cells ( $>40$ days storage). In neutrophils, more than 400 distinct proteins could be identified in MPs released from neutrophils either in suspension (stimulated with AMLF, formyl-methionyl-leucyl phenylalanine), or adherent to a HUVEC monolayer, with only 223 proteins overlapping in the two MP-fractions [10]. Thus, mass spectrometry can uncover baseline and induced MP proteomes and pinpoint MP candidate biomarkers.

\section{Proteomics of human circulating microparticles identifies galectin-3 binding protein as a candidate biomarker for pathogenic microparticles}

The human MP proteome studies to date have explored the proteome of the whole pool of plasma MPs, erythrocyte- (eMPs) or platelet-derived MPs (PMPs) isolated directly from plasma, or MPs generated in vitro from isolated platelets or granulocytes in healthy or diseased individuals [10-12, 37-41, 46, 48-56]. As can be seen from Table 1 the pre-analytical and analytical protocols differ between the studies on almost all points and caution regarding their interpretation is therefore warranted. The major observations are highlighted and put into perspective in the following sections.

\section{Healthy individuals}

Smalley et al. [38] observed that G3BP was more abundant in the total fraction of plasma MPs compared to the subfraction of platelet-derived MPs from healthy individuals. They also found an increased abundance of immunoglobulins, complement proteins, alpha-2-macroglobulin (A2M), and CD5 antigen-like protein in the total MP fraction. Together with this observation, the absence or very low abundance of G3BP in other proteomic studies of platelets, platelet- or erythrocytederived MPs during healthy conditions suggests that G3BP expression is a distinct feature of MPs derived from nucleated cells such as leukocytes and/or endothelial cells [37, 38, 41, 46, 49-53, 56]. In contrast to G3BP, A2 $\mathrm{M}$ was also found in erythrocyte-derived MPs and PMPs [52]. 


\section{Systemic lupus erythematosus}

SLE is an immune complex-mediated autoimmune disease linked to defective clearance of apoptotic cells, and circulating MPs are putative sources and traffickers of extracellular nuclear autoantigens. Østergaard et al. observed that circulating MPs from patients with SLE had increased quantities of G3BP compared to patients with systemic sclerosis and rheumatoid arthritis and to healthy controls $[11,57]$. Ficolin-2, 14-3-3, $\beta-2-$ glycoprotein-I, CD5 antigen-like protein, immunoglobulins, and complement proteins were also overabundant in SLE-MPs. Notably, A2M was not overexpressed. Overall, these findings suggested that more circulating MPs in SLE are of apoptotic origin and derive from leukocytes or endothelial cells, carry large quantities of autoantigens and immune complexes (ICs), and, finally, that G3BP is a distinguishing feature of such pathogenic MPs.

\section{Venous thromboembolism}

Ramacciotti et al. [12] found that G3BP was also enriched in plasma MPs in nine patients with deep venous thrombosis (DVT) compared to nine patients with leg pain without DVT and to six healthy controls. Also, complement proteins, immunoglobulins, A2M, CD5 antigen-like protein, clusterin, and polymeric immunoglobulin receptor were increased in MPs from DVT patients. It should be noted that in this study the samples were analysed three times and only A2M and G3BP were consistently identified in all three experiments in each patient. DeRoo et al. [58] explored the role of G3BP and galectin-3 (gal3 ) in a mouse model of venous thromboembolism (VTE). Here they found G3BP in MPs, platelets, red blood cells, the thrombi and vein walls but not in leukocytes using quantitative immunoblotting and qRT-PCR. They did not observe a difference between the VTE and non-VTE mice regarding G3BP-MP quantities. Interestingly, significant levels of G3BP was found on the endothelium and bound to gal-3 on neutrophils facilitating their migration and extravasation. Gal-3 appeared to drive the vascular inflammation by stimulating the production of interleukin- 6 and chemokine (C-C motif) ligand 2 (CCL2). This links both G3BP and gal-3 to inflammatory changes in VTE. In experimental VTE using four baboons, the same research group showed that fibrinogen and $\alpha_{1}$-antichymotrypsin were enriched and some immunoglobulins were down-regulated two days after a $6 \mathrm{~h}$ occlusion of the iliac veins [59]. G3BP was not enriched. The MP proteome in experimental rat VTE showed increased abundance of fibrinogens, macroglobulins including A2M, and immunoglobulins [60]. Thus, animal studies do not reproduce the findings of a G3BP-increase in human DVT; the interpretation of this discrepancy remains elusive.

\section{Atherosclerosis}

Several roles for MPs in the acceleration of atherosclerosis and arterial thrombosis have been proposed [4]. Mayr et al. [61] explored the proteome of MPs from atherosclerotic plaques. They found that the MPs were primarily of leukocyte origin based on the presence of surface markers (CD14, CD11c, CD18, CD51, and CD36), but that some also derived from smooth muscle cells and erythrocytes. Interestingly, immunoglobulins were also very abundant but primarily confined to the interior of the MPs, especially in MPs of macrophage origin, and the marked difference between antigen specificity compared to plasma immunoglobulins suggested a specific binding of antibodies to MP antigens [61]. Little et al. [39] characterized the plasma MP proteome in 42 individuals, the majority with a history of cardiovascular disease, hypertension, and diabetes. A core set of proteins was identified and correlated to gender and age, but, surprisingly, not to the other available cardiovascular risk factors. G3BP did not correlate with age and gender corroborating the utility of G3BP as an age/gender independent disease biomarker. Interestingly, at the same time the research group filed a patent application on G3BP as soluble biomarker for cardiovascular disease (patent application title and number: Galectin-3-Binding Protein as a Biomarker of Cardiovascular Disease, 20100055723) and recently observed that plasma G3BP correlated to mortality in coronary artery disease [62]. In patients with lacunar infarction, plasma MPs were characterized and correlated to clinical outcome and compared to healthy controls [55]. A differential expression of 43 proteins was observed. In particular, myelin basic protein was upregulated. G3BP and CD5 antigen-like protein were downregulated, while A2M showed minimal alterations. It should be noted that the MP isolation protocol differs significantly from the other protocols and most likely also includes a large proportion of exosomes (see Table 1 for details). Thus, based on a limited amount of data, an overexpression of G3BP on MPs in atherosclerosis or cardiovascular disease cannot be demonstrated.

\section{A distinct overlap of the disease-associated microparticle proteomes in SLE and DVT patients}

Despite the fact that so far only few and small studies with significant differences in methodology have been conducted, there is a striking overlap of MP-overexpressed proteins across the different disease entities, in particular G3BP, immunoglobulins, complement proteins, A2M, and CD5 antigen-like protein. Interestingly, G3BP and CD5 antigen-like protein were the only two common proteins found upregulated in plasma MPs, DVT, and SLE patient MP proteomes, while the common denominators in DVT and SLE were G3BP and A2M 
$[11,12,38]$. Accordingly, G3BP is the only consistently enriched protein across these three studies. Additionally, immunoglobulins and complement proteins were also found consistently enriched in the DVT and SLE MPs. SLE patients exhibit an increased platelet and coagulation activity and increased incidence of venous thrombosis. Altogether, these observations implicate MPs expressing these proteins as being involved in the disease pathogenesis and also suggest that these particular MPs originate from nucleated cells $[10,63,64]$.

\section{Galectin-3-binding protein: structure, formation, and function}

The formation, targets and biological functions of galectin-3-binding protein (also named Mac-2-binding protein) are yet not well defined. G3BP has been detected in several types of body fluids, such as serum, breast milk and semen, and is expressed in most tissues [18, 32]. In plasma, G3BP circulates in association with MPs as well as large soluble ring-like oligomers $30-40 \mathrm{~nm}$ in diameter with a molecular size larger than $1000 \mathrm{kDa}[18,39]$. In vitro, G3BP is up-regulated by interferon (IFN)- $\alpha$ and $-\gamma$, viruses, and double-stranded polynucleotides $[14,23$, 65]. Accordingly, plasma G3BP have been found elevated in diseases with increased IFN activity such as human immunodeficiency virus infection, chronic viral hepatitis, and SLE, but also in various types of solid cancers, Behcet's disease, and rheumatoid arthritis [14, 66-72]. G3BP serves as a scavenger receptor which interacts with several targets [16]. It was originally identified (and named) in the search for gal-3 glycoprotein ligands [16, $17,20]$. Galectins are a group of 15 different carbohydrate binding proteins (lectins), termed galectin-1 (gal-1) to galectin-15 [13]. Gal-1 and gal-3 are involved in cell growth, adhesion, differentiation, inflammation, fibrosis, apoptosis, and metastasis [13]. Galectins bind via carbohydrate binding domains to galactosides on cell surfaces and on extracellular glycoproteins [64]. G3BP is heavy glycosylated and, as a major receptor for gal-3 and gal1 , it may be crucial for galectin mediated biological processes [18, 73]. Additionally, G3BP exhibits independent and selective binding to components of the extracellular matrix of the basement membrane in solid-phase assays, i.e. it interacts with collagen V and VI, fibronectin and nidogen, but not with laminin-1, fibulin-1 and -2, perlecan, and BM-40 [18]. G3BP also mediates cell-cell adhesion through binding to $\beta 1$-integrin and LPS-dependently to $\mathrm{CD} 14$, and the protein seems to exert regulatory roles in immunity, e.g. through up-regulation of major histocompatibility class I (MHC-I) molecules and through the ability to stimulate natural killer (NK-) cells [18, 19, 32].

Collectively, G3BP is involved in the initiation and promotion of cell-cell adhesion and pro-inflammatory signalling cascades in viral infections, cancer (including metastasis), coagulation and haemostasis, and autoimmunity.

\section{The origin, role, and biomarker potential of G3BP-expressing microparticles}

The proteomic studies of plasma MPs from disease entities characterized by some degree of intravascular cell death and activation combined with systemic and local inflammation, activation of the coagulation system, and thrombophilia suggest a common MP pathological proteome profile. Besides G3BP, these profiles also include immunoglobulins, complement proteins, A2M, and CD5 antigen-like protein. These observations suggest that MPs are tagged for removal during pathological states and that the overabundance of these proteins could reflect common upstream pathogenic processes such as increased cell activation and apoptosis in the circulating cells or endothelium along with activation of the coagulation and immune system.

\section{The cellular origin of G3BP-expressing microparticles}

The cellular origin of G3BP-positive MPs under various conditions remains to be established. G3BP has been identified in high abundance in leukocytes, endothelial cells, and red blood cells and has been undetectable or present at a low abundance in platelets or plateletderived MPs in humans. The G3BP gene expression is also dominant in type I IFN-activated neutrophils and peripheral blood mononuclear cells (PBMCs) in SLE patients [66]. In contrast, in a mouse model (C57CL/6 strain) G3BP was detected in platelets, circulating MPs, red blood cells, but not leukocytes [58]. This underscores the difficulty of translating animal studies of the molecular pathology of thrombosis (and SLE) to human systems. The available data from studies in humans strongly suggest that the majority of the G3BP-overexpressing MPs in the circulation originate from neutrophils, monocytes, and endothelial cells.

\section{The mechanisms behind microparticle G3BP-overexpression}

G3BP overexpression on MPs most likely reflects the state of the parental cells, i.e. activation, stress, or, death. During these processes, G3BP is relocated into MPs and/ or binds to upregulated MP surface molecules e.g. to gal-1 or gal-3. Generally, the composition and packaging of MPs is highly coordinated [7]. Increased G3BP associated with MPs may be caused by increased loading of G3BP during MP production in parent cells and tissues and/or increased binding of exogenous G3BP, e.g. from the circulation, to released MPs. As an example of differential expression, Dalli et al. only found low quantities 
of G3BP in MPs from fMLF-stimulated neutrophils and G3BP could not be detected in MPs originating from neutrophils stimulated by HUVECs. In contrast to the low G3BP expression generated by these stimuli, type I IFNs induce G3BP gene expression in vitro, and exploratory studies of IFN gene signatures in neutrophils and PBMCs from SLE patients identified G3BP as one of only few highly IFN-inducible genes [66, 74, 75]. However, it is unsettled if IFN activation results in increased G3BP in/on MPs, or, indeed, if systemic inflammation per se leads to increase in plasma-G3BP and a corresponding increase in binding of G3BP to MPs. Several studies suggest that increased MP-G3BP expression is part of the defence against viral infection [23, 74]. One possibility is that the virus-infected cells increase G3BP expression to eliminate viral particles by shedding G3BP-tagged MPs containing viral particles that are recognized and removed by professional phagocytes in the reticuloendothelial system. In our proteomic studies G3BP was the only IFN-inducible protein overabundant in SLEMPs indicating that other mechanisms than type I IFNinduction controls MP-G3BP expression [11]. It is likely that G3BP overexpression simply reflects an increased number of apoptotic cell-derived circulating MPs in SLE patients. Lectins serve as sensors of apoptotic cells due to surface glycosylation changes on such cells. Accordingly, galectins significantly increase their binding to apoptotic cells, and G3BP subsequently binds to the galectins [63, 64]. In support of the notion of G3BP MPs being of apoptotic origin we found that G3BP is co-localized with glomerular immune complex deposits and on singular round structures in kidney biopsies from SLE patients [8]. As mentioned previously, apoptotic cells and MPs are major sources of extracellular autoantigens in the immune complex deposits, and the significant presence of G3BP in these deposits and on circulating MPs strongly corroborate the apoptotic origin of G3BP MPs $[8,76,77]$. Studies of the expression of G3BP on MPs from cells undergoing apoptosis or stimulated with IFN are needed to clarify the relative contributions of different cellular processes to the increase of G3BP-positive MPs in SLE and vascular disease.

\section{The role of G3BP-expressing microparticles in systemic lupus erythematosus}

SLE is a systemic autoimmune disease capable of affecting most organ systems including the kidneys where glomerulonephritis (termed lupus nephritis, LN) is the major severe manifestation. Development of SLE is linked to defective clearance of apoptotic cells leading to an excess of highly auto-immunogenic cellular debris (apoptotic bodies and MPs) triggering anti-nuclear autoimmunity [8, 78-82]. An early important pathological feature is the occurrence of immune complex deposits in the glomerular basement membrane (GBM) that activate the complement system and incite inflammation [76, 83, 84]. Thus it is highly interesting to clarify the origin of these ICs in order to prevent their production and deposition and the subsequent inflammation and progression of LN. The origin of the ICs in the GBM is, however, unsettled. They may derive either from the circulation or locally in the glomeruli or even from a combination. The identification of G3BP as part of large MP-IC assemblies circulating in the blood of SLE patients is highly interesting in this context [57]. As mentioned, G3BP binds strongly to gal- 1 and gal- 3 and integrins, which are upregulated on endothelial cells, and also to basement membrane proteins [18]. Accordingly, G3BP may endow these MP-ICs with significant cell- and basement membrane adhesive properties in addition to affecting activation of immune cells. By binding to the endothelium and the extracellular matrix of the basement membrane G3BP may contribute to the MP-IC deposition and accumulation in the kidney $[18,19,23,32,57,85]$. This may be aggravated by increased type I IFN-induced G3BP. Under normal conditions, G3BP may be part of the normal cell and MP clearance. However, the increased type I IFNs and G3BP in combination with a constant excess of highly altered immunogenic MPs may be crucial for the breakdown of tolerance and sustained systemic autoimmunity of SLE. Whether G3BP also could have adjuvant effects on the cellular arms of the immune system enhancing the stimulation by the MP-associated autoantigens is unclear. In any case, because of this multitude of possible pathogenetic mechanisms involving G3BP, this protein is an interesting putative therapeutic target [77]. By targeting G3BP the MP-autoantigenic "fuel" could be blocked reducing the IC deposition, activation of the complement system and the cellular arms of the immune system. This approach could prove more specific and thus less toxic and less prone to side effects than traditional immuno-suppressants.

\section{Galectin-3-binding protein and venous thromboembolism} VTE occurs as a result of blood stasis, hypercoagulability, and increased pro-coagulant adhesion molecules on endothelial cells in conjunction with inflammation. Circulating MPs are pro-coagulant and can contribute to thrombosis by their exposure of TF and phosphatidylserine [4]. Soluble, cell-, and MP-exposed gal-3 and G3BP may modulate thrombogenesis, particularly the involved inflammatory cascades, and are interesting future therapeutic targets [13].

It has been become apparent that inflammation contributes to VTE. In a study by deRoo and coworkers, activated platelets expressed P-selectin and PSGL-1 that lead 
to increased leukocyte adhesion and thrombus formation. Binding of G3BP to gal-1 on the platelets resulted in an increased P-selectin expression and promoted platelet activation and thrombogenesis [58]. This may trigger increased MP-G3BP release and perpetuate the platelet activation. Also, G3BP and gal-3 affected the cell-cell adhesion on the thrombus-endothelial interface and the thrombus itself and were increased on the endothelium in a mouse model of VTE [58]. Additionally, in this study, during early VTE gal-3 was greatly increased and G3BP and gal-3 co-localized in the leukocyte/endothelial cell interface and leukocytes were attached to the vein wall. The thrombus size correlated with gal-3 and interleukin- 6 in the vein wall, and the vein wall inflammatory changes seemed driven by triggering of IL- 6 by gal- 3 and the proinflammatory chemokine CCL2. In patients with acute VTE elevated levels of circulating G3BP were found. Accordingly, G3BP seems to play a role in the pathogenesis of VTE and thrombophilia. In SLE increased rates of VTE are a prominent feature and G3BP may be a novel thrombophilia risk factor independent of the presence of anti-phospholipid antibodies. We have also observed that increased levels of plasma G3BP were a predictor of venous thromboembolic events in SLE patients independent of the presence of anti-phospholipid antibodies (unpublished data). Clarification of the role of G3BP needs further exploration in VTE. If further studies support an important role for G3BP in thrombosis the development of G3BP or gal-3 blocking compounds seems to be attractive future therapeutic approaches.

\section{G3BP-expressing microparticles as future biomarkers}

Generally, in inflammatory and thrombotic diseases G3BP-overexpressing MPs appear to be promising diagnostic or prognostic biomarkers as well as biomarkers of disease activity. Additionally, G3BP-MPs could be sensitive novel biomarkers of apoptotic activity relevant in autoimmunity, cardiovascular disease, and cancer.

Specifically, MP-associated G3BP may represent several advantages compared with soluble plasma G3BP used as biomarkers. Total plasma G3BP and G3BP-MPs levels do not completely mirror each other [14]. This suggests that G3BP is differentially expressed in different compartments in the blood. Mass spectrometry provides a global measure of G3BP in a whole pool of pelleted MPs. Different populations of G3BP-positive MPs based on G3BP and PS surface densities can be discerned in the circulation in both healthy individuals and SLE patients using flow cytometry [14]. Only one of the flow cytometrically identified G3BP-positive populations correlated with plasma G3BP levels, while there were no apparent correlation between plasma G3BP and the MP G3BP quantities obtained by mass spectrometry. In SLE, G3BP-MP expression distinguished SLE patients from healthy controls and from patients with other autoimmune diseases (systemic sclerosis and rheumatoid arthritis) and it seems worthwhile to test the diagnostic potential in larger prospective cohorts of patients presenting with signs of systemic connective tissue disease [11]. In relation to disease activity, clinical, or immunological manifestations, there was no correlation to the G3BP-MP quantities obtained by mass spectrometry [14]. The concentrations of one of the flow cytometrically identified sub-populations (G3BP and annexin $\mathrm{V}$ positive) correlated to anti-dsDNA levels but not to disease activity or to clinical or serological manifestations [8]. This links G3BP-expressing MPs to polyclonal activation of plasma cells or the effects thereof, but their use as biomarkers of disease activity seems limited in SLE.

In VTE increased levels of d-dimer are sensitive markers of VTE, but are, however, not specific. G3BP-MPs may contribute to the specificity, perhaps as part of an MP-DVT profile with A2M and CD5 antigen-like protein. In VTE little focus has been on monitoring, damage and outcome and a role for G3BP as a biomarker here is difficult to predict.

Plasma levels of G3BP may reflect macrophage activity and type I IFN activity $[14,15]$. To a certain degree this may also be the case for G3BP-expressing MPs. Type I IFNs are associated with subclinical markers of atherosclerosis in vitro $[86,87]$. Thus it interesting that the plasma concentrations of G3BP are significantly associated with the degree of subclinical atherosclerosis in patients with HIV and hepatitis C [15]. This may also be the case in SLE, where increased type I IFNs and accelerated atherosclerosis are dominant features. Recently, plasma G3BP levels were independently associated with long-term cardiovascular mortality [62]. Little et al. [39] do not report on the putative correlations between the G3BP MP quantities and cardiovascular comorbidities, which would be interesting area to explore for future atherosclerosis biomarker studies.

\section{Conclusions}

The unbiased dissection of the circulating MP proteome has led to novel discoveries of candidate MP proteins associated with venous thrombosis and systemic lupus erythematosus. These include G3BP, immunoglobulins, complement, A2M, and CD5 antigen-like protein. In general, the candidate MP biomarkers provide new tools to explore the roles of MPs in disease pathogenesis and as biomarkers. The restricted number of differentially expressed MP proteins fit the notion that the proteins reflect the specific state of their parental cells. Accordingly, the MP-proteins serve as biomarkers for MPs that either reflect or have direct roles in 
the disease pathogenesis, i.e. patho-phenotypical or pathogenic MPs, respectively. In SLE, high IFN-activity and improper clearance of apoptotic cells may lead to the overabundance of apoptotic-derived MPs with high expression of G3BP that form large circulating immune complexes. G3BP on the surface of the MPs most likely facilitates the deposition of the MP-ICs in the kidney promoting glomerulonephritis. MP-G3BP may thus have a direct role in SLE pathogenesis, while also serving as a biomarker in lupus nephritis, and of circulating apoptotic-derived MPs. While the proteomic studies clearly associate MP-G3BP overexpression with SLE and deep venous thrombosis, we anticipate that the future potential of G3BP and the other MP candidate biomarkers may be even far greater in cancer and chronic viral diseases. A major limitation of the proteome discovery studies is often the small number of patients and controls. With the identification of the MP-biomarkers, the proteins can now be easily incorporated in large MPbiomarker panels together with cell-specific markers, annexin V, or other MP molecules of interest enabling high-throughput targeted MP studies in large cohorts of patients. Such large studies are now feasible and highly warranted in the fields of coagulation and hemostasis, infection, cancer, and autoimmunity.

\section{Abbreviations \\ 1-D: one-dimensional; 2-D: two-dimensional; ADP: adenosine diphosphate; A2M: alpha-2-macroglobulin; CCL2: chemokine (C-C motif) ligand 2; CD: cluster of differentiation; DNA: deoxyribonucleic acid; eMPs: erythrocyte- microparticles; fMLF: formyl-methionyl-leucyl phenylalanine; Gal-3: galectin-3; G3BP: galectin-3-binding protein; GBM: glomerular basement membrane; HUVECs: human umbilical vascular endothelial cells; ICAT: isotope-coded affinity tag; Ics: immune complexes; IFN-a: interferon-a; LC-MS/MS: liquid chromatography-tandem mass spectrometry; ITRAQ: isobaric tags for relative and absolute quantitation; LPS: lipopolysaccharide; LN: lupus nephritis; MHC: major histocompatibility class; MALDI-TOF: matrix-assisted laser desorption/ ionization time of flight; MVs: microvesicles; MPs: microparticles; mRNA: messenger RNA; miRNA: microRNA; MS: mass spectrometry; NK: natural killer; PAl: plasminogen activator inhibitor; PBMCs: peripheral blood mononuclear cells; PMPs: platelet-derived MPs; RNA: ribonucleic acid; SLE: systemic lupus erythematosus; TF: tissue factor; TNF: tumor necrosis factor; VTE: venous thromboembolism.}

\section{Authors' contributions}

All authors meet the authorship qualifications as specified in the journal publication guidelines. $C T N, O \varnothing$, and $\mathrm{NHHH}$ contributed to the conception, design, analysis, interpretation of data, drafting and revision the manuscript. SJ and NSR contributed to the interpretation of data and critically revised the manuscript for important intellectual content. All authors read and approved the final manuscript.

\footnotetext{
Author details

${ }^{1}$ Copenhagen Lupus and Vasculitis Clinic, Centre for Rheumatology and Spine Diseases, Rigshospitalet, Copenhagen University Hospital, Blegdamsvej 9, 2100 Copenhagen $\varnothing$, Denmark. ${ }^{2}$ Department of Autoimmunology and Biomarkers, Statens Serum Institut, Artillerivej 5, 2300 Copenhagen, Denmark. ${ }^{3}$ Department of Clinical Biochemistry and Pharmacology, Odense University Hospital, University of Southern Denmark, Søndre Boulevard 29, 5000 Odense, Denmark.
}

\section{Acknowledgements}

None.

\section{Competing interests}

The authors declare that they have no competing interests.

\section{Publisher's Note}

Springer Nature remains neutral with regard to jurisdictional claims in published maps and institutional affiliations.

Received: 25 November 2016 Accepted: 31 March 2017

Published online: 08 April 2017

\section{References}

1. Yanez-Mo M, Siljander PR, Andreu Z, Zavec AB, Borras FE, Buzas El, et al. Biological properties of extracellular vesicles and their physiological functions. J Extracell Vesicles. 2015;4:27066.

2. Piccin A, Murphy WG, Smith OP. Circulating microparticles: pathophysiology and clinical implications. Blood Rev. 2007;21:157-71.

3. Khurana S, Wu J, Verma N, Verma S, Raghunandan R, Manischewitz J, et al. H5N1 virus-like particle vaccine elicits cross-reactive neutralizing antibodies that preferentially bind to the oligomeric form of influenza virus hemagglutinin in humans. J Virol. 2011;85:10945-54.

4. Rautou PE, Vion AC, Amabile N, Chironi G, Simon A, Tedgui A, et al. Microparticles, vascular function, and atherothrombosis. Circ Res. 2011;109:593-606.

5. Dieker J, Tel J, Pieterse E, Thielen A, Rother N, Bakker M et al. Circulating apoptotic microparticles in SLE patients drive the activation of DC subsets and prime neutrophils for NETosis. Arthritis Rheumatol; 2015.

6. Jy W, Horstman LL, Jimenez JJ, Ahn YS, Biro E, Nieuwland R, et al. Measuring circulating cell-derived microparticles. J Thromb Haemost. 2004;2:1842-51.

7. Nielsen CT. Circulating microparticles in systemic lupus erythematosus. Dan Med J. 2012;59:B4548.

8. Nielsen CT, Ostergaard O, Rekvig OP, Sturfelt G, Jacobsen S, Heegaard NH. Galectin-3 binding protein links circulating microparticles with electron dense glomerular deposits in lupus nephritis. Lupus. 2015;24:1150-60.

9. Dalli J, Norling LV, Montero-Melendez T, Federici CD, Lashin H, Pavlov AM, et al. Microparticle alpha-2-macroglobulin enhances pro-resolving responses and promotes survival in sepsis. EMBO Mol Med. 2014;6:27-42.

10. Dalli J, Montero-Melendez T, Norling LV, Yin X, Hinds C, Haskard D, et al. Heterogeneity in neutrophil microparticles reveals distinct proteome and functional properties. Mol Cell Proteomics. 2013;12:2205-19.

11. Ostergaard O, Nielsen CT, Iversen LV, Tanassi JT, Knudsen S, Jacobsen S, et al. Unique protein signature of circulating microparticles in systemic lupus erythematosus. Arthritis Rheum. 2013;65:2680-90.

12. Ramacciotti E, Hawley AE, Wrobleski SK, Myers DD Jr, Strahler JR, Andrews PC, et al. Proteomics of microparticles after deep venous thrombosis. Thromb Res. 2010;125:e269-74.

13. Diaz JA, Ramacciotti E, Wakefield TW. Do galectins play a role in venous thrombosis? a review. Thromb Res. 2010;125:373-6.

14. Nielsen CT, Lood C, Ostergaard O, Iversen LV, Voss A, Bengtsson A, et al. Plasma levels of galectin-3-binding protein reflect type I interferon activity and are increased in patients with systemic lupus erythematosus. Lupus Sci Med. 2014;1:e000026.

15. Shaked I, Hanna DB, Gleissner C, Marsh B, Plants J, Tracy D, et al. Macrophage inflammatory markers are associated with subclinical carotid artery disease in women with human immunodeficiency virus or hepatitis C virus infection. Arterioscler Thromb Vasc Biol. 2014;34:1085-92.

16. Hohenester E, Sasaki T, Timpl R. Crystal structure of a scavenger receptor cysteine-rich domain sheds light on an ancient superfamily. Nat Struct Biol. 1999;6:228-32

17. Koths K, Taylor E, Halenbeck R, Casipit C, Wang A. Cloning and characterization of a human Mac-2-binding protein, a new member of the superfamily defined by the macrophage scavenger receptor cysteinerich domain. J Biol Chem. 1993:268:14245-9. 
18. Sasaki T, Brakebusch C, Engel J, Timpl R. Mac-2 binding protein is a celladhesive protein of the extracellular matrix which self-assembles into ring-like structures and binds $\beta 1$ integrins, collagens and fibronectin. EMBO J. 1998;17:1606-13.

19. Inohara H, Akahani S, Koths K, Raz A. Interactions between galectin-3 and Mac-2-binding protein mediate cell-cell adhesion. Cancer Res. 1996;56:4530-4.

20. Tinari N, Kuwabara I, Huflejt ME, Shen PF, lacobelli S, Liu FT. Glycoprotein 90K/MAC-2BP interacts with galectin-1 and mediates galectin-1-induced cell aggregation. Int J Cancer. 2001;91:167-72.

21. lacobelli S, Bucci I, D'Egidio M, Giuliani C, Natoli C, Tinari N, et al. Purification and characterization of a $90 \mathrm{kDa}$ protein released from human tumors and tumor cell lines. FEBS Lett. 1993;319:59-65.

22. lacobelli S, Ullrich A, Tinari N, Ortona L, Tamburrini E, D'Egidio M, et al. The 90K tumor-associated antigen and clinical progression in human immunodeficiency virus infection. J Acquir Immune Defic Syndr Hum Retrovirol. 1995;10:450-6.

23. Grassadonia A, Tinari N, Fiorentino B, Suzuki K, Nakazato M, De TM, et al. The $90 \mathrm{~K}$ protein increases major histocompatibility complex class I expression and is regulated by hormones, gamma-interferon, and double-strand polynucleotides. Endocrinology. 2004;145:4728-36.

24. Fusco O, Querzoli P, Nenci I, Natoli C, Brakebush C, Ullrich A, et al. 90K (MAC-2 BP) gene expression in breast cancer and evidence for the production of $90 \mathrm{~K}$ by peripheral-blood mononuclear cells. Int J Cancer. 1998;79:23-6

25. Artini M, Natoli C, Tinari N, Costanzo A, Marinelli R, Balsano C, et al. Elevated serum levels of $90 \mathrm{~K} / \mathrm{MAC}-2 \mathrm{BP}$ predict unresponsiveness to alpha-interferon therapy in chronic HCV hepatitis patients. J Hepatol. 1996:25:212-7.

26. Groschel B, Braner JJ, Funk M, Linde R, Doerr HW, Cinatl J Jr, et al. Elevated plasma levels of 90K (Mac-2 BP) immunostimulatory glycoprotein in HIV1-infected children. J Clin Immunol. 2000;20:117-22.

27. lacobelli S, Natoli C, D’Egidio M, Tamburrini E, Antinori A, Ortona L. Lipoprotein $90 \mathrm{~K}$ in human immunodeficiency virus-infected patients: a further serologic marker of progression. J Infect Dis. 1991;164:819.

28. Senaldi G, Peakman M, Natoli C, Hussain MJ, Gallati H, McManus T, et al. Relationship between the tumour-associated antigen 90K and cytokines in the circulation of persons infected with human immunodeficiency virus. J Infect. 1994;28:31-9.

29. Natoli C, lacobelli S, Kohn L. The immune stimulatory protein $90 \mathrm{~K}$ increases major histocompatibility complex class I expression in a human breast cancer cell line. Biochem Biophys Res Commun. 1996;225:617-20.

30. Grassadonia A, Tinari N, lurisci I, Piccolo E, Cumashi A, Innominato P, et al. 90K (Mac-2 BP) and galectins in tumor progression and metastasis. Glycoconj J. 2004;19:551-6.

31. Lin TW, Chang HT, Chen $\mathrm{CH}$, Chen $\mathrm{CH}$, Lin SW, Hsu TL, et al. Galectin-3 binding protein and galectin-1 interaction in breast cancer cell aggregation and metastasis. J Am Chem Soc. 2015;137:9685-93.

32. Ullrich A, Sures I, D'Egidio M, Jallal B, Powell TJ, Herbst R, et al. The secreted tumor-associated antigen $90 \mathrm{~K}$ is a potent immune stimulator. $J$ Biol Chem. 1994;269:18401-7.

33. Marchetti A, Tinari N, Buttitta F, Chella A, Angeletti CA, Sacco R, et al. Expression of $90 \mathrm{~K}$ (Mac-2 BP) correlates with distant metastasis and predicts survival in stage I non-small cell lung cancer patients. Cancer Res. 2002;62:2535-9.

34. White MJ, Roife D, Gomer RH. Galectin-3 binding protein secreted by breast cancer cells inhibits monocyte-derived fibrocyte differentiation. J Immunol. 2015;195:1858-67.

35. Tinari N, Lattanzio R, Querzoli P, Natoli C, Grassadonia A, Alberti S, et al. High expression of $90 \mathrm{~K}$ (Mac-2 BP) is associated with poor survival in node-negative breast cancer patients not receiving adjuvant systemic therapies. Int J Cancer. 2009;124:333-8.

36. Rea A, Palmieri G, Tinari N, Natoli C, Tagliaferri P, Morabito A, et al. $90 \mathrm{~K}$ is a serum marker of poor-prognosis in non-hodgkins-lymphoma patients. Oncol Rep. 1994;1:723-5.

37. Jin M, Drwal G, Bourgeois T, Saltz J, Wu HM. Distinct proteome features of plasma microparticles. Proteomics. 2005;5:1940-52.

38. Smalley DM, Root KE, Cho H, Ross MM, Ley K. Proteomic discovery of 21 proteins expressed in human plasma-derived but not platelet-derived microparticles. Thromb Haemost. 2007;97:67-80.
39. Little KM, Smalley DM, Harthun NL, Ley K. The plasma microparticle proteome. Semin Thromb Hemost. 2010;36:845-56.

40. Ostergaard O, Nielsen CT, Iversen LV, Jacobsen S, Tanassi JT, Heegaard NH. Quantitative proteome profiling of normal human circulating microparticles. J Proteome Res. 2012;11:2154-63.

41. Milioli M, Ibanez-Vea M, Sidoli S, Palmisano G, Careri M, Larsen MR. Quantitative proteomics analysis of platelet-derived microparticles reveals distinct protein signatures when stimulated by different physiological agonists. J Proteomics. 2015;121:56-66.

42. Heegaard NH, Ostergaard O, Bahl JM, Overgaard M, Beck HC, Rasmussen LM, et al. Important options available-from start to finish-for translating proteomics results to clinical chemistry. Proteomics Clin Appl. 2015;9:235-52

43. Kreimer S, Belov AM, Ghiran I, Murthy SK, Frank DA, Ivanov AR. Massspectrometry-based molecular characterization of extracellular vesicles: lipidomics and proteomics. J Proteome Res. 2015;14:2367-84.

44. Peterson DB, Sander T, Kaul S, Wakim BT, Halligan B, Twigger S, et al. Comparative proteomic analysis of PAI-1 and TNF-alpha-derived endothelial microparticles. Proteomics. 2008;8:2430-46.

45. Bernimoulin M, Waters EK, Foy M, Steele BM, Sullivan M, Falet H, et al. Differential stimulation of monocytic cells results in distinct populations of microparticles. J Thromb Haemost. 2009;7:1019-28.

46. Shai E, Rosa I, Parguina AF, Motahedeh S, Varon D, Garcia A. Comparative analysis of platelet-derived microparticles reveals differences in their amount and proteome depending on the platelet stimulus. J Proteomics. 2012;76:287-96.

47. Prudent M, Crettaz D, Delobel J, Seghatchian J, Tissot JD, Lion N. Differences between calcium-stimulated and storage-induced erythrocytederived microvesicles. Transfus Apher Sci. 2015;53:153-8.

48. Bastos-Amador P, Royo F, Gonzalez E, Conde-Vancells J, Palomo-Diez L, Borras FE, et al. Proteomic analysis of microvesicles from plasma of healthy donors reveals high individual variability. J Proteomics. 2012;75:3574-84.

49. Garcia BA, Smalley DM, Cho H, Shabanowitz J, Ley K, Hunt DF. The platelet microparticle proteome. J Proteome Res. 2005;4:1516-21.

50. Rubin O, Crettaz D, Canellini G, Tissot JD, Lion N. Microparticles in stored red blood cells: an approach using flow cytometry and proteomic tools. Vox Sang. 2008;95:288-97.

51. Piersma SR, Broxterman HJ, Kapci M, de Haas RR, Hoekman K, Verheul HM, et al. Proteomics of the TRAP-induced platelet releasate. J Proteomics. 2009;72:91-109.

52. Dean WL, Lee MJ, Cummins TD, Schultz DJ, Powell DW. Proteomic and functional characterisation of platelet microparticle size classes. Thromb Haemost. 2009;102:711-8.

53. Bosman GJ, Lasonder E, Groenen-Dopp YA, Willekens FL, Werre JM. The proteome of erythrocyte-derived microparticles from plasma: new clues for erythrocyte aging and vesiculation. J Proteomics. 2012;76:203-10.

54. Chaichompoo P, Kumya P, Khowawisetsut L, Chiangjong W, Chaiyarit S, Pongsakul N, et al. Characterizations and proteome analysis of plateletfree plasma-derived microparticles in beta-thalassemia/hemoglobin $\mathrm{E}$ patients. J Proteomics. 2012;76:239-50.

55. Datta A, Chen CP, Sze SK. Discovery of prognostic biomarker candidates of lacunar infarction by quantitative proteomics of microvesicles enriched plasma. PLoS ONE. 2014;9:e94663.

56. Capriotti AL, Caruso G, Cavaliere C, Piovesana S, Samperi R, Lagana A. Proteomic characterization of human platelet-derived microparticles. Anal Chim Acta. 2013;776:57-63.

57. Nielsen CT, Ostergaard O, Stener L, Iversen LV, Truedsson L, Gullstrand $B$, et al. Increased lgG on cell-derived plasma microparticles in systemic lupus erythematosus is associated with autoantibodies and complement activation. Arthritis Rheum. 2012;64:1227-36.

58. DeRoo EP, Wrobleski SK, Shea EM, Al-Khalil RK, Hawley AE, Henke PK, et al. The role of galectin-3 and galectin-3-binding protein in venous thrombosis. Blood. 2015;125:1813-21.

59. Abdullah NM, Kachman M, Walker A, Hawley AE, Wrobleski SK, Myers DD, et al. Microparticle surface protein are associated with experimental venous thrombosis: a preliminary study. Clin Appl Thromb Hemost. 2009;15:201-8

60. Watts JA, Lee YY, Gellar MA, Fulkerson MB, Hwang SI, Kline JA. Proteomics of microparticles after experimental pulmonary embolism. Thromb Res. 2012;130:122-8. 
61. Mayr M, Grainger D, Mayr U, Leroyer AS, Leseche G, Sidibe A, et al. Proteomics, metabolomics, and immunomics on microparticles derived from human atherosclerotic plaques. Circ Cardiovasc Genet. 2009;2:379-88.

62. Gleissner CA, Erbel C, Linden F, Domschke G, Akhavanpoor M, Doesch $A O$, et al. Galectin-3 binding protein plasma levels are associated with long-term mortality in coronary artery disease independent of plaque morphology. Atherosclerosis. 2016;251:94-100.

63. Bilyy RO, Shkandina T, Tomin A, Munoz LE, Franz S, AntonyukV, et al. Macrophages discriminate glycosylation patterns of apoptotic cell-derived microparticles. J Biol Chem. 2012;287:496-503.

64. Beer A, Andre S, Kaltner H, Lensch M, Franz S, Sarter K, et al. Human galectins as sensors for apoptosis/necrosis-associated surface changes of granulocytes and lymphocytes. Cytom A. 2008;73:139-47.

65. Marth C, Dreps A, Natoli C, Zeimet AG, Lang T, Widschwendter M, et al. Effects of type-I and - II interferons on 90K antigen expression in ovarian carcinoma cells. Int J Cancer. 1994;59:808-13.

66. Baechler EC, Batliwalla FM, Karypis G, Gaffney PM, Ortmann WA, Espe $\mathrm{KJ}$, et al. Interferon-inducible gene expression signature in peripheral blood cells of patients with severe lupus. Proc Natl Acad Sci USA. 2003:100:2610-5.

67. Cheung KJ, Libbrecht L, Tilleman K, Deforce D, Colle I, Van Vlierberghe H. Galectin-3-binding protein: a serological and histological assessment in accordance with hepatitis C-related liver fibrosis. Eur J Gastroenterol Hepatol. 2010;22:1066-73.

68. lacobelli S, Sismondi P, Giai M, D'Egidio M, Tinari N, Amatetti C, et al. Prognostic value of a novel circulating serum 90K antigen in breast cancer. $\mathrm{Br}$ J Cancer. 1994;69:172-6.

69. Lee YJ, Kang SW, Song JK, Park JJ, Bae YD, Lee EY, et al. Serum galectin-3 and galectin-3 binding protein levels in Behcet's disease and their association with disease activity. Clin Exp Rheumatol. 2007;25:S41-5.

70. Ohshima S, Kuchen S, Seemayer CA, Kyburz D, Hirt A, Klinzing S, et al. Galectin 3 and its binding protein in rheumatoid arthritis. Arthritis Rheum. 2003:48:2788-95.

71. Tinari N, Natoli C, D'Ostilio N, Ghinelli F, Sighinolfi L, Ortona L, et al. 90K (Mac-2 BP) predicts CD4 decline in human immunodeficiency virusinfected patients with CD4 counts above $200 \times 10(6)$ cells/L. Arch Pathol Lab Med. 1998;122:178-81.

72. Zeimet AG, Natoli C, Herold M, Fuchs D, Windbichler G, Daxenbichler G, et al. Circulating immunostimulatory protein $90 \mathrm{~K}$ and soluble interleukin2-receptor in human ovarian cancer. Int J Cancer. 1996;68:34-8.

73. Rosenberg I, Cherayil BJ, Isselbacher KJ, Pillai S. Mac-2-binding glycoproteins. Putative ligands for a cytosolic beta-galactoside lectin. J Biol Chem. 1991;266:18731-6.

74. Kyogoku C, Smiljanovic B, Grun JR, Biesen R, Schulte-Wrede U, Haupl T, et al. Cell-specific type I IFN signatures in autoimmunity and viral infection: what makes the difference? PLoS ONE. 2013;8:e83776.
75. Bennett L, Palucka AK, Arce E, Cantrell V, Borvak J, Banchereau J, et al. Interferon and granulopoiesis signatures in systemic lupus erythematosus blood. J Exp Med. 2003;197:711-23.

76. Seredkina N, van der Vlag J, Berden J, Mortensen E, Rekvig OP. Lupus nephritis: enigmas, conflicting models and an emerging concept. Mol Med. 2013;19:161-9.

77. Nielsen CT, Rasmussen NS, Heegaard NH, Jacobsen S. "Kill" the messenger: Targeting of cell-derived microparticles in lupus nephritis. Autoimmun Rev. 2016;15:719-25.

78. Beyer C, Pisetsky DS. The role of microparticles in the pathogenesis of rheumatic diseases. Nat Rev Rheumatol. 2010;6:21-9.

79. Munoz LE, Lauber K, Schiller M, Manfredi AA, Herrmann M. The role of defective clearance of apoptotic cells in systemic autoimmunity. Nat Rev Rheumatol. 2010;6:280-9.

80. Casciola-Rosen LA, Anhalt G, Rosen A. Autoantigens targeted in systemic lupus erythematosus are clustered in two populations of surface structures on apoptotic keratinocytes. J Exp Med. 1994;179:1317-30.

81. Sisirak V, Sally B, D'Agati V, Martinez-Ortiz W, Ozcakar ZB, David J, et al. Digestion of chromatin in apoptotic cell microparticles prevents autoimmunity. Cell. 2016;166:88-101.

82. Dieker J, Hilbrands L, Thielen A, Dijkman H, Berden JH, van der Vlag J. Enhanced activation of dendritic cells by autologous apoptotic microvesicles in MRL/Ipr mice. Arthritis Res Ther. 2015;17:103.

83. Weening JJ, D'Agati VD, Schwartz MM, Seshan SV, Alpers CE, Appel GB, et al. The classification of glomerulonephritis in systemic lupus erythematosus revisited. J Am Soc Nephrol. 2004;15:241-50.

84. Borchers AT, Leibushor N, Naguwa SM, Cheema GS, Shoenfeld Y, Gershwin ME. Lupus nephritis: a critical review. Autoimmun Rev. 2012;12:174-94.

85. Ullal AJ, Reich CF III, Clowse M, Criscione-Schreiber LG, Tochacek M, Monestier M, et al. Microparticles as antigenic targets of antibodies to DNA and nucleosomes in systemic lupus erythematosus. J Autoimmun. 2011;36:173-80.

86. Somers EC, Zhao W, Lewis EE, Wang L, Wing JJ, Sundaram B, et al. Type I interferons are associated with subclinical markers of cardiovascular disease in a cohort of systemic lupus erythematosus patients. PLOS ONE. 2012; 7:e37000

87. Thacker SG, Zhao W, Smith CK, Luo W, Wang H, Vivekanandan-Giri A, et al. Type I interferons modulate vascular function, repair, thrombosis, and plaque progression in murine models of lupus and atherosclerosis. Arthritis Rheum. 2012;64:2975-85.

\section{Submit your next manuscript to BioMed Central and we will help you at every step:}

- We accept pre-submission inquiries

- Our selector tool helps you to find the most relevant journal

- We provide round the clock customer support

- Convenient online submission

- Thorough peer review

- Inclusion in PubMed and all major indexing services

- Maximum visibility for your research

Submit your manuscript at www.biomedcentral.com/submit 